\title{
Isomerization of the Isoprene Hydroxy Nitrates and Formation of Orthonitrite Compounds
}

Gabriel da Silva

Submitted date: 25/06/2019 Posted date: 26/06/2019

Licence: CC BY-NC-ND 4.0

Citation information: da Silva, Gabriel (2019): Isomerization of the Isoprene Hydroxy Nitrates and Formation of Orthonitrite Compounds. ChemRxiv. Preprint.

Atmospheric oxidation of isoprene produces significant yields of eight unique nitrate 11 compounds, each with a $\beta$ - or $\delta$-hydroxy group. These isoprene hydroxy nitrates (ISOPNs) 12 significantly impact upon global NOx budgets, $\mathrm{O} 3$ levels, and aerosol formation. 13 Uncertainties exist, however, in our understanding of ISOPN chemistry, particularly in their 14 yields from the reaction of isoprene peroxyl radicals with NO. This study describes novel 15 isomerization reactions of the ISOPNs, identified through the application of computational 16 chemistry techniques. These reactions produce saturated polycyclic orthonitrite compounds 17 via attack of the R-NO2 group on the vinyl moiety. For the $\delta$-hydroxy nitrates, low-energy 18 isomerization pathways exist to six-membered ring compounds that are around $5 \mathrm{kcal} \mathrm{mol-1} 19$ exothermic. These reactions proceed with barriers around $15 \mathrm{kcal} \mathrm{mol}-1$ below the 20 respective peroxyl radical + $\mathrm{NO}$ reactants and yield orthonitrites that can further isomerize 21 to $\beta$-hydroxy ISOPNs. Moreover, the $\delta$-hydroxy nitrates can directly interconvert with their $\beta 22$ substituted counterparts via NO3 group migration, with barriers that are lower yet. It follows 23 that $\beta$-hydroxy nitrates may be stabilized in the $\delta$-hydroxy form, and vice versa. Moreover, 24 the lowest-energy pathway for dissociation of the $\delta$-hydroxy ISOPNs is for the formation of $25 \beta$-hydroxy alkoxyl radicals, and because of this established branching fractions between the 26 various isoprene peroxyl radicals may require re-evaluation. The results presented here also 27 suggest that ISOPNs may be stabilized to some extent in their saturated orthonitrite forms, 28 which has implications for both the total nitrate yield and for their subsequent removal by $29 \mathrm{OH}, 03$, and photolysis.

File list (3)

Isoprene Orthonitrites June 2019.pdf (483.39 KiB)

view on ChemRxiv • download file

Isoprene Orthonitrites Supporting Information.pdf (289.40 KiB)

view on ChemRxiv - download file 
1 Isomerization of the Isoprene Hydroxy Nitrates and Formation of Orthonitrite

2 Compounds

Gabriel da Silva*

Department of Chemical and Biomolecular Engineering, The University of Melbourne, Victoria 3010 Australia

*gdasilva@unimelb.edu.au

\section{ABSTRACT}

Atmospheric oxidation of isoprene produces significant yields of eight unique nitrate compounds, each with a $\beta$ - or $\delta$-hydroxy group. These isoprene hydroxy nitrates (ISOPNs) significantly impact upon global $\mathrm{NO}_{x}$ budgets, $\mathrm{O}_{3}$ levels, and aerosol formation. Uncertainties exist, however, in our understanding of ISOPN chemistry, particularly in their yields from the reaction of isoprene peroxyl radicals with NO. This study describes novel isomerization reactions of the ISOPNs, identified through the application of computational chemistry techniques. These reactions produce saturated polycyclic orthonitrite compounds via attack of the $\mathrm{R}-\mathrm{NO}_{2}$ group on the vinyl moiety. For the $\delta$-hydroxy nitrates, low-energy isomerization pathways exist to six-membered ring compounds that are around $5 \mathrm{kcal}^{\mathrm{mol}} \mathbf{l}^{-1}$ exothermic. These reactions proceed with barriers around $15 \mathrm{kcal} \mathrm{mol}^{-1}$ below the respective peroxyl radical + NO reactants and yield orthonitrites that can further isomerize to $\beta$-hydroxy ISOPNs. Moreover, the $\delta$-hydroxy nitrates can directly interconvert with their $\beta$ substituted counterparts via $\mathrm{NO}_{3}$ group migration, with barriers that are lower yet. It follows that $\beta$-hydroxy nitrates may be stabilized in the $\delta$-hydroxy form, and vice versa. Moreover, the lowest-energy pathway for dissociation of the $\delta$-hydroxy ISOPNs is for the formation of $\beta$-hydroxy alkoxyl radicals, and because of this established branching fractions between the various isoprene peroxyl radicals may require re-evaluation. The results presented here also suggest that ISOPNs may be stabilized to some extent in their saturated orthonitrite forms, which has implications for both the total nitrate yield and for their subsequent removal by $\mathrm{OH}, \mathrm{O}_{3}$, and photolysis. 


\section{Introduction}

Isoprene hydroxy nitrates (ISOPNs) are produced globally in large quantities through the photochemical oxidation of isoprene. These compounds primarily arise from the sequential addition of ${ }^{\circ} \mathrm{OH}$ and $\mathrm{O}_{2}$ to isoprene to produce the isoprene peroxyl radicals, which then react with NO to yield stabilized ISOPNs along with the dominant products: isoprene alkoxyl radicals $+\mathrm{NO}_{2}{ }^{1}$ Isoprene is the second most emitted hydrocarbon to Earth's atmosphere ${ }^{2}$ and because of this ISOPNs represent significant $\mathrm{NO}_{x}$ reservoirs as well as chain-terminating free radical sinks. ${ }^{3-6}$ Branching between nitrate stabilization vs. chemically activated fragmentation to alkoxyl radicals is a key parameter in atmospheric chemical mechanisms, and has been studied extensively for isoprene. ${ }^{7}$ Likewise, the photochemical degradation of ISOPNs is also important, and key atmospheric sinks such as the reaction with $\mathrm{OH}$ have been widely investigated. ${ }^{8}$

Despite being intensively studied, there remain significant uncertainties in our understanding of ISOPN chemistry. Total isoprene nitrate yields from peroxyl radical + NO chemistry have recently been estimated at $9 \%$, with uncertainties placing it in the 6 to $14 \%$ range. ${ }^{7}$ Earlier studies report total ISOPN yields anywhere from 4 to $14 \% .3,4,9-12$ When considering the individual ISOPN isomers - of which there are eight - Paulot et al. ${ }^{3}$ estimated yields of $6.7 \%$ for those with $\beta$-hydroxy functionality compared to $24 \%$ for those with $\delta$-hydroxy groups. The source of this variability remains unclear. Furthermore, theoretical attempts to model even the simplest peroxyl radical + NO reactions have proven difficult, due to uncertainties involved in the initial peroxy nitrite to nitrate rearrangement, and difficulties in modelling the collisional deactivation of the resultant nitrate vs. fragmentation. ${ }^{13-15}$

In order to gain further insight into the stabilization and fragmentation reactions of the ISOPN isomers, this study investigates their isomerization and decomposition pathways using computational chemistry techniques. Pathways are revealed for isomerization of the isoprene hydroxy nitrates to orthonitrite compounds, as well as for the direct interconversion of select hydroxy nitrates, all proceeding with barriers below the conventional reaction pathways. The chemistry revealed here provides new forms of the ISOPNs that may be collisionally stabilized and also opens up new pathways for the interconversion and decomposition of chemically activated peroxyl radical $+\mathrm{NO}$ intermediates.

\section{Methods}

Stationary points and product sets on the $\mathrm{C}_{5} \mathrm{O}_{4} \mathrm{NH}_{9}$ potential energy surface were optimized at the M06-2X/6-31G(2df,p) level of theory. All structures were confirmed to be stationary points possessing no imaginary frequencies (for minima) or one imaginary frequency corresponding to motion along the reaction coordinate (for transition states). Furthermore, 
intrinsic reaction coordinate scans were used to verify transition state connectivity. For instances where multiple conformations exist, both for minima and transition states, only the most stable one is reported. High-level energies were subsequently obtained at the G3X-K level of theory, ${ }^{16}$ which uses M06-2X/6-31G(2df,p) structures in a series of singlepoint wave function theory energy calculations from HF theory through to $\operatorname{CCSD}(T)$, with basis sets of incrementally decreasing size. Final G3X-K energies also incorporate an empirical scaling factor, and are expected to be accurate to within around $0.7 \mathrm{kcal} \mathrm{mol}^{-1}$ for barrier height calculations. All reported calculations were carried out within the Gaussian 09 program suite. ${ }^{17}$ Coordinates for optimized structures are reported as Supporting Information.

\section{Results and Discussion}

There exist eight unique ISOPN isomers that can form from the addition of NO to the isoprene peroxyl radicals. These isomers are illustrated in Figure 1 , where the naming convention adopted in this study is also introduced. Four ISOPN isomers feature $\beta-\mathrm{OH}$ substituents, with the vinyl group either $\alpha$ (1,2-ISOPN and 4,3-ISOPN) or $\gamma$ (2,1-ISOPN and $3,4-$ ISOPN) to the nitrate group. The former arise from "external" $\mathrm{OH}$ addition in isoprene whereas the latter arise from "internal" $\mathrm{OH}$ addition. The remaining four ISOPN isomers all possess $\delta$-OH substituents, and differ only in position of the methyl group and orientation about the double bond (i.e., E or Z).

The 1,2-ISOPN and 4,3-ISOPN isomers are formed from what are thought to be the dominant isoprene peroxyl radicals, ${ }^{3}$ and are identical but for placement of the methyl group. Although the yields of these nitrates are relatively low, the importance of their parent peroxyl radicals makes them significant ISOPNs. The four $\delta$-OH ISOPNs arise from isoprene peroxyl radicals that are predicted to form in lower yields, but account for a significant fraction of the total isoprene nitrates due to their higher individual nitrate yields. ${ }^{3}$ Finally, the 2,1- and 3,4-ISOPN isomers are the least significant, as they form at low yields from minor (internal $\mathrm{OH}$ addition) isoprene peroxyl radicals.

This study reveals that all eight ISOPNs can isomerize to polycyclic ring compounds via attack of the $\mathrm{R}-\mathrm{NO}_{2}$ group on the vinyl moiety. The resultant compounds possess an orthonitrite structure, and are referred to here as the isoprene orthonitrites (IONs). Orthonitrites are stable yet little-studied compounds, ${ }^{18}$ named after the hypothetical substance sodium orthonitrite, $\mathrm{Na}_{3} \mathrm{NO}_{3} .{ }^{19}$ Structures for the IONs are shown in Figure 2, with the transition states leading to their formation depicted in Figure 3. For the ISOPNs in which the nitrate group is located $\beta$ to the vinyl group, the IONs possess a bridged sixmembered ring structure (ION $1-4)$. For the ISOPNs with the nitrate group $\gamma$ to the vinyl group, the IONs demonstrate a bridged seven-membered ring structure. 
Table 1 lists standard enthalpies of formation and entropies for the IONs and ISOPNs, calculated at the G3X-K level of theory. Firstly, we see no major differences between the enthalpies and entropies of the ISOPN isomers. The six-membered IONs $(1-4)$ all exhibit enthalpies that are lower than the ISOPNs; on average, they are more stable by ca. $4 \mathrm{kcal}$ $\mathrm{mol}^{-1}$. However, these IONs are also consistently lower in entropy, due to loss of internal rotors. The aggregate effect is for these IONs to be lower than the ISOPNs in free energy by around $1 \mathrm{kcal} \mathrm{mol}^{-1}$. The seven-membered IONs $(5-8)$ are less-stable than the other orthonitrites by around $3 \mathrm{kcal} \mathrm{mol}^{-1}$ in terms of enthalpy. Accordingly, they are approximately isoenthalpic with the ISOPNs, and are on average about $2 \mathrm{kcal} \mathrm{mol}^{-1}$ higher in terms of free energy.

Theoretical energy diagrams illustrating how the ISOPNs isomerize to the IONs are shown in Figures 4-6 and S1 - S5, and are discussed below. These diagrams also include the barrierless dissociation channel to the corresponding alkoxyl radical $+\mathrm{NO}_{2}$, as well as the energy of the peroxyl radical (+ NO) from which the ISOPNs are produced.

Figure 4 provides an energy diagram for 1,2-ISOPN. The corresponding diagram for 4,3ISOPN is included as Figure S1 of the Supporting Information. Formation of 1,2-ISOPN from the $\mathrm{RO}_{2}+\mathrm{NO}$ reaction is around $50 \mathrm{kcal} \mathrm{mol}^{-1}$ exothermic. Dissociation to the $\mathrm{RO}+\mathrm{NO}_{2}$ channel proceeds with a barrier of $41 \mathrm{kcal} \mathrm{mol}^{-1}$ and no adiabatic transition state, placing it 8 $\mathrm{kcal} \mathrm{mol}^{-1}$ below the entrance channel energy (11 $\mathrm{kcal} \mathrm{mol}^{-1}$ for 4,3-ISOPN). As a result, the dominant fate of chemically activated 1,2-ISOPN produced at around standard temperature and pressure is for dissociation to $\mathrm{RO}+\mathrm{NO}_{2}$, although some collisional deactivation of the nitrate adduct is known to take place. As shown in Figure 4, 1,2-ISOPN can isomerize to two orthonitrite compounds, ION-1 and ION-2, which are stereoisomers of each other. These compounds sit below the isoprene nitrate that they originate from in both enthalpy and free energy, and would therefore dominate the $\mathrm{C}_{5} \mathrm{O}_{4} \mathrm{NH}_{9}$ population if they were allowed to equilibrate. Indeed, respective equilibrium constants for forming ION-1 and ION-2 from 1,2ISOPN are 17.6 and 4.3 at $298 \mathrm{~K}$ (the values for 4,3-ISOPN yielding ION-3 and ION-4 are 86.2 and 4.9).

The barrier heights for isomerization of 1,2-ISOPN to ION-1 and ION-2 are both $35 \mathrm{kcal} \mathrm{mol}^{-1}$, which is over $14 \mathrm{kcal} \mathrm{mol}^{-1}$ below the forming $\mathrm{RO}_{2}+\mathrm{NO}$ energy, and lower than the $\mathrm{RO}+$ $\mathrm{NO}_{2}$ exit channel by more than $6 \mathrm{kcal} \mathrm{mol}^{-1}$ (energetics for the related 4,3-ISOPN isomer are similar, only with slightly higher isomerization barriers). Given the favorable thermodynamics for ION formation, as well as the relatively low isomerization barriers, we hypothesize that the orthonitrite forms will contribute at least some of the stabilized $\mathrm{RO}_{2}+$ $\mathrm{NO}$ adduct yield in the atmosphere for the major external $\mathrm{OH}$ addition $\beta$-OH peroxyl radicals.

There exist four $\delta$-OH peroxyl radicals produced from $\mathrm{OH}, \mathrm{O}_{2}$ addition to isoprene, which lead to the $E$ and $Z$ forms of 1,4-ISOPN and 4,1-ISOPN. Energy diagrams for 1,4-(E)-ISOPN and 1,4-(Z)-ISOPN are shown in Figures 5 and 6, with the corresponding 4,1-(E/Z)-ISOPN 
diagrams included as Figures $\mathrm{S} 2$ and S3. ISOPN formation from the $\delta$-OH peroxyl radicals is around $52-54 \mathrm{kcal} \mathrm{mol}^{-1}$ exothermic, with dissociation of the ISOPNs to $\mathrm{RO}+\mathrm{NO}_{2}$ requiring around $43 \mathrm{kcal} \mathrm{mol}^{-1}$. The chemically activated $\mathrm{RO}_{2}+\mathrm{NO} \rightarrow \mathrm{RO}+\mathrm{NO}_{2}$ process therefore occurs with a barrier that is around $10 \mathrm{kcal} \mathrm{mol}^{-1}$ below the reactants. The energetics are similar to the peroxyl radical reactions discussed above, and no strong argument could be made for the higher yields observed experimentally. Again, the $\delta$-OH ISOPNs can isomerize to orthonitrites, with barriers of around $35-38 \mathrm{kcal} \mathrm{mol}^{-1}$, and these species are predicted to be thermodynamically favoured over the nitrates ( $298 \mathrm{~K}$ equilibrium constants in the range of $0.5-173)$.

For the internal addition $\beta$-OH ISOPNs (2,1- and 3,4-ISOPN), where the nitrate group is located $\gamma$ to the vinyl moiety, the available isoprene nitrite isomers (ION-5 through ION-8) are structurally different from those discussed above, and are consistently higher in energy. The energy diagrams for isomerization of these minor ISOPNs are provided as Figures $\mathrm{S} 4$ and S5. In both instances the energetics of ISOPN formation via $\mathrm{RO}_{2}+\mathrm{NO}$ and dissociation to $\mathrm{RO}$ $+\mathrm{NO}_{2}$ are similar to the other peroxyl radicals, with the isoprene nitrates formed with around $54 \mathrm{kcal} \mathrm{mol}^{-1}$ of excess vibrational energy, and at around $10 \mathrm{kcal} \mathrm{mol}^{-1}$ above the alkoxyl radical exit channel. These ISOPNs can isomerize to two isoprene orthonitrite stereoisomers, with barriers between 32 and $36 \mathrm{kcal} \mathrm{mol}^{-1}$; again this is similar to the preceding cases. However, the ensuing isoprene orthonitrites are either at or above the ISOPN enthalpies (by up to $3 \mathrm{kcal} \mathrm{mol}^{-1}$ ), and are even higher in terms of free energy (equilibrium constants are $0.1-0.0001$ ). As such, the collisional deactivation of 2,1- and 3,4-ISOPN as the orthonitrite forms should be less significant than for the other ISOPN isomers, and is likely to be a minor channel at best. The orthonitrite compounds formed from 2,1- and 3,4-ISOPN do, however, show some unique decomposition channels. This is illustrated for ION-6 (2,1-ISOPN) in Figure 7. An intramolecular hydrogen shift, with barrier of $38.5 \mathrm{kcal} \mathrm{mol}^{-1}$ relative to 2,1-ISOPN, can lead to the generation of hydroxyacetone with vinyl nitrite. Moreover, elimination of formaldehyde can also take place, leading to the formation of a hydroxy vinyl nitrite compound with barrier $35.5 \mathrm{kcal} \mathrm{mol}^{-1}$ relative to the nitrate. In 2,1-ISOPN the ION-5 isomer can similarly eliminate formaldehyde but cannot form hydroxyacetone due to the orientation of the hydroxyl group. Analogous mechanisms are also available for ION-7 and ION-8 arising from 3,4-ISOPN. Note that although the internal $\mathrm{OH}$ addition isoprene nitrates are themselves almost insignificant $(\sim 1 \%$ of the total isoprene $+\mathrm{OH}$ product yield), the alkoxyl radicals that they generate are thought to be of some importance ( $8 \%$ in $\mathrm{NO}_{x}$ dominated environments). Significantly, the present work shows that decomposition channels for these nitrates are available below the conventional alkoxyl radical $+\mathrm{NO}_{2}$ pathways. These reactions all lead to closed-shell products that sequester inorganic nitrogen, and they may need to be incorporated into future chemical mechanisms.

The results presented here have broad implications when it comes to assessing the fate of the major isoprene peroxyl radicals. Firstly, these peroxyl radicals can react with NO and be 
stabilised to at least some extent as orthonitrites, in addition to the conventionally considered nitrates. Because the IONs are fully saturated, they are likely to be unreactive towards $\mathrm{O}_{3}$, and considerably less reactive towards $\mathrm{OH}$ than their ISOPN counterparts. The structure-activity relationship methods of Atkinson, ${ }^{20}$ implemented within the AOPWIN (v1.92) code, for instance, predict rate coefficients of $4.5 \times 10^{-12} \mathrm{~cm}^{3}$ molecule ${ }^{-1} \mathrm{~s}^{-1}$ for ION$1 / 2+\mathrm{OH}$, and $4.7 \times 10^{-12} \mathrm{~cm}^{3}$ molecule $\mathrm{e}^{-1} \mathrm{~s}^{-1}$ for $\mathrm{ION}-3 / 4+\mathrm{OH}$ (reaction is dominated by $\mathrm{C}-\mathrm{H}$ abstraction from the site adjacent to the hydroxyl group). These can be compared to values of around $1.0 \times 10^{-10} \mathrm{~cm}^{3}$ molecule $\mathrm{e}^{-1} \mathrm{~s}^{-1}$ for the $\delta$-hydroxy ISOPNs $+\mathrm{OH}$ and up to $0.6 \times 10^{-10}$ $\mathrm{cm}^{3}$ molecule ${ }^{-1} \mathrm{~s}^{-1}$ for the $\beta$-hydroxy ISOPNs $+\mathrm{OH} .{ }^{3,19}$ Moreover, the IONs do not possess the nitrate chromophore, removing a further atmospheric sink (i.e., photolysis). The IONs are also predicted to display significantly different IR spectra from the ISOPNs (Figures S7 and S8), which may allow for the detection in the laboratory or the field.

Secondly, and potentially of most significance, the present work discloses that the major $\beta$ $\mathrm{OH}$ isoprene nitrates can interchange with their $\delta \mathrm{-OH}$ isomers; this process is illustrated in Figure 8 for the 1,4 and 1,2 isomers (a corresponding diagram for the 4,1 and 4,2 isomers is provided as Figure 56 ). In addition to being able to isomerize via the common orthonitrites, direct $\mathrm{NO}_{2}$ migration reactions are available with even lower barriers (see Figure 9 for transition state structures). These isomerization reactions are predicted to require barriers more than $10 \mathrm{kcal} \mathrm{mol}^{-1}$ below the alkoxyl radical $+\mathrm{NO}_{2}$ dissociation thresholds, and result in scrambling of the $\delta$ and $\beta$ substituted isoprene hydroxy nitrates. One consequence is that the $\beta$-OH peroxyl radicals may actually react with $\mathrm{NO}$ to produce $\delta$-OH nitrates (and vice versa). This leads us to hypothesize a new mechanism for the much higher individual yields of $\delta$ vs. $\beta$ substituted hydroxy nitrates observed in the photochemical oxidation of isoprene. Conversely, the $\delta \mathrm{OH}$ isoprene peroxyl radicals may react with NO to produce $\beta$-OH substituted alkoxyl radicals $\left(+\mathrm{NO}_{2}\right)$. Indeed, Figure 8 illustrates that this would be the lowest-energy decomposition pathway for these energized nitrate intermediates. A nonnegligible yield of $\beta-\mathrm{OH}$ alkoxyl radicals from the $\delta$-OH peroxyl radicals would require us to re-evaluate the initial branching fractions for $\mathrm{O}_{2}$ addition to the isoprene- $\mathrm{OH}$ adducts, which have been assigned mainly on the basis of these alkoxyl radical products under $\mathrm{NO}_{x}$ dominant conditions. If $\delta \mathrm{-OH}$ peroxyl radical yields are higher than currently thought this would also revise down the fitted yields of $\delta \mathrm{-OH}$ nitrates. Revised branching fractions for the isoprene peroxyl radicals would have significant implications for isoprene chemistry under $\mathrm{NO}_{x}$-deficient conditions, where hydroperoxide formation and peroxyl radical isomerization becomes important. In particular, higher $\delta \mathrm{OH}$ peroxyl radical yields would provide increased opportunities for HPALD formation, which can lead to cascading $\mathrm{OH}$ radical generation. ${ }^{22-24}$ Despite recent advances, our description of isoprene chemistry in remote environments is still lacking, particularly with respect to $\mathrm{OH}$ radical regeneration, ${ }^{25-28}$ and this new chemistry could provide a further mechanism to help bridge this gap. 
228 Supporting Information Available: Coordinates for optimized structures. Energy diagrams and reaction schemes for ISOPN isomers not included in the manuscript.

Acknowledgements: This work was supported by the Australian Research Council (ARC)

232 through the Future Fellowship (FT130101304) scheme. 


\section{References}

1. Roberts, J. M. The Atmospheric Chemistry of Organic Nitrates. Atmos. Environ. 1990, 24A, $243-287$.

2. Guenther, A. B.; Jiang, X.; Heald, C. L.; Sakulyanontvittaya, T.; Duhl, T.; Emmons, L. K.; Wang, X. The Model of Emissions of Gases and Aerosols from Nature Version 2.1 (MEGAN2.1): An Extended and Updated Framework for Modelling Biogenic Emissions. Geosci. Model Dev. 2015, 5, 1471-1492.

3. Paulot, F.; Crounse, J. D.; Kjaergaard, H. G.; Kroll, J. H.; Seinfeld, J. H.; Wennberg, P. O. Isoprene Photooxidation: New Insights into the Production of Acids and Organic Nitrates. Atmos. Chem. Phys. 2009, 9, 1479-1501.

4. Lockwood, A. L.; Shepson, P. B.; Fiddler, M. N.; Alaghmand, M. Isoprene Nitrates: Preparation, Searation, Identification, Yields, and Atmospheric Chemistry. Atmos. Chem. Phys. 2010, 10, 61696178.

5. Fisher, J. A.; Jacob, D. J.; Travis, K. R.; Kim, P. S.; Marais, E. A.; Miller, C. C.; Yu, K.; Zhu, L.; Yantosca, R. M.; Sulprizio, M. P. et al. Organic Nitrate Chemistry and its Implications for Nitrogen Budgets in an Isoprene- and Monoterpene-Rich Atmosphere: Constraints from Aircraft (SEAC4RS) and GroundBased (SOAS) Observations in the Southeast US. Atmos. Chem. Phys. 2016, 16, 5969-5991.

6. Romer, P. S.; Duffey, K. C.; Wooldridge, P. J.; Allen, H. M.; Ayres, B. R.; Brown, S. S.; Brune, W. H.; Crounse, J. D.; de Gouw, J.; Draper, D. C. et al. The Lifetime of Nitrogen Oxides in an IsopreneDominated Forest. Atmos. Chem. Phys. 2016, 16, 7623-7637.

7. Xiong, F.; McAvey, K. M.; Pratt, K. A.; Groff, C. J.; Hostetler, M. A.; Lipton, M. A.; Starn, T. K.; Seeley, J. V.; Bertman, S. B.; Teng, A. P. et al. Observation of Isoprene Hydroxynitrates in the Southeastern United States and Implications for the Fate of NOx. Atmos. Chem. Phys. 2015, 15, 11257-11272.

8. Lee, L.; Teng, A. P.; Wennberg, P. O.; Crounse, J. D.; Cohen, R. C. On Rates and Mechanisms of OH and $\mathrm{O}_{3}$ Reactions with Isoprene-Derived Hydroxy Nitrates. J. Phys. Chem. A 2014, 118, 1622-1637.

9. Chen, X.; Hulbert, D.; Shepson, P. B. Measurement of the Organic Nitrate Yield from OH Reaction with Isoprene. J. Geophys. Res. 1998, 103, 25563-25568.

10. Tuazon, E. C.; Atkinson, R. A Product Study of the Gas-Phase Reaction of Isoprene with the OH Radical in the Presence of $\mathrm{NO}_{x}$.

11. Sprengnether, M.; Demerjian, K. L.; Donahue, N. M.; Anderson, J. G. Product Analysis of the $\mathrm{OH}$ Oxidation of Isoprene and 1,3-Butadiene in the Presence of NO. J. Geophys. Res. 2002, 107, doi: 10.1029/2001JD00716.

12. Patchen, A. K.; Pennino, M. J.; Elrod, M. J. Direct Kinetics Study of the Product-Forming Channels of the Reaction of Isoprene-Derived Hydroxyperoxy Radicals with NO. Int. J. Chem. Kinet. 2007, 39, 353361.

13. Lohr, L. L.; Barker, J. R.; Shroll, R. M. Modeling the Organic Nitrate Yields in the Reaction of Alkyl Peroxy Radicals with Nitric Oxide. 1. Electronic Structure Calculations and Thermochemistry. J. Phys. Chem. A 2003, 107, 7429-7433.

14. Barker, J. R.; Lohr, L. L.; Shroll, R. M.; Reading, S. Modeling the Organic Nitrate Yields in the Reaction of Alkyl Peroxy Radicals with Nitric Oxide. 2. Reaction Simulations. J. Phys. Chem. A 2003, 107, 74347444.

15. Zhang, J.; Dransfield, T.; Donahue, N. M. On the Mechanism for Nitrate Formation via the Peroxy Radical + NO Reaction. J. Phys. Chem. A 2004, 108, 9082-9095.

16. da Silva, G. G3X-K Theory: A Composite Theoretical Method for Thermochemical Kinetics. Chem. Phys. Lett. 2013, 558, 109-113.

17. Gaussian 09, Revision B.01, Frisch, M. J.; Trucks, G. W.; Schlegel, H. B.; Scuseria, G. E.; Robb, M. A.; Cheeseman, J. R.; Scalmani, G.; Barone, V.; Mennucci, B.; Petersson, G. A. et al., Gaussian, Inc., Wallingford CT, 2010.

18. Rudchenko, V. F.; Ignatov, S. M.; Chervin, I. I.; Kostyanovsky, R. G. Asymmetric nitrogen - 70. Geminal Systems - 44. Trialkoxyamines (orthonitrites). Synthesis and Properties. Tetrahedron 1988, 44, 22332239.

19. Jansen, M. $\mathrm{Na}_{3} \mathrm{NO}_{3}-$ Not an Orthonitrite. Angew. Chem. Int. Ed. 1976, 15, 376-377. 
20. Atkinson, R. A. Structure-Activity Relationship for the Estimation of Rate Constants for the Gas-Phase Reactions of $\mathrm{OH}$ Radicals with Organic Compounds. Int. J. Chem. Kinet. 1987, 19, 799-828. 
324 Table 1. Standard enthalpies of formation at $0 \mathrm{~K}\left(\Delta_{f} H^{\circ}\right)$ and $298 \mathrm{~K}\left(\Delta_{f} H^{\circ}{ }_{298}\right)$ and entropies $325\left(S^{\circ}{ }_{298}\right)$ for the isoprene hydroxy nitrates (ISOPNs) and isoprene orthonitrites (IONs). 326 Enthalpies in $\mathrm{kcal} \mathrm{mol}^{-1}$ and entropies in cal mol${ }^{-1} \mathrm{~K}^{-1}$, calculated the $\mathrm{G} 3 \mathrm{X}-\mathrm{K}$ level of theory.

\begin{tabular}{cccc} 
& $\Delta_{f} H^{\circ}{ }_{0}$ & $\Delta_{f} H^{\circ}{ }_{298}$ & $S^{\circ}{ }_{298}$ \\
\hline 1,2-ISOPN & -54.1 & -62.6 & 98.6 \\
2,1-ISOPN & -57.1 & -65.7 & 99.4 \\
3,4-ISOPN & -55.6 & -64.1 & 101.7 \\
4,3-ISOPN & -55.3 & -63.7 & 101.2 \\
1,4-(E)-ISOPN & -55.0 & -63.3 & 103.2 \\
1,4-(Z)-ISOPN & -54.7 & -63.2 & 99.5 \\
$4,1-(E)-I S O P N$ & -53.4 & -61.5 & 106.0 \\
$4,1-(Z)-I S O P N$ & -54.2 & -62.7 & 99.7 \\
ION-1 & -57.4 & -67.1 & 89.2 \\
ION-2 & -56.4 & -66.0 & 90.1 \\
ION-3 & -59.6 & -69.2 & 90.4 \\
ION-4 & -58.1 & -67.5 & 91.6 \\
ION-5 & -55.3 & -65.0 & 88.5 \\
ION-6 & -54.0 & -63.7 & 88.1 \\
ION-7 & -54.9 & -64.5 & 88.9 \\
ION-8 & -55.7 & -65.4 & 88.7 \\
\hline
\end{tabular}


330

331

332

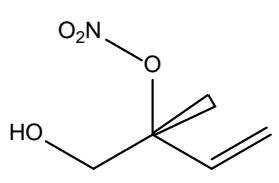

1,2-ISOPN

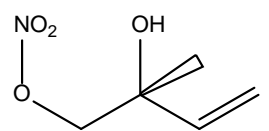

2,1-ISOPN<smiles>C=C(C)C(CO)O[N+](=O)[O-]</smiles>

4,3-ISOPN

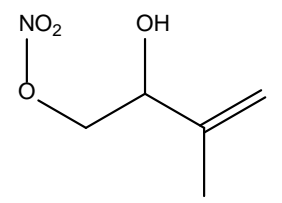

3,4-ISOPN<smiles>C/C(=C/CO[N+](=O)[O-])CO</smiles>

1,4-(E)-ISOPN

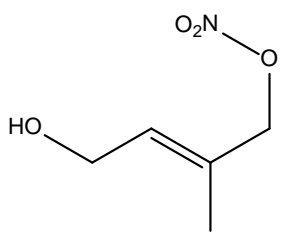

4,1-(E)-ISOPN<smiles>C/C(=C/CO[N+](=O)[O-])CO</smiles>

1,4-(Z)-ISOPN

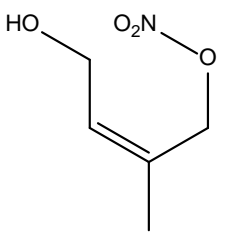

4,1-(Z)-ISOPN

334 Figure 1. The isoprene hydroxy nitrate (ISOPN) isomers and naming convention.

335

336

337 

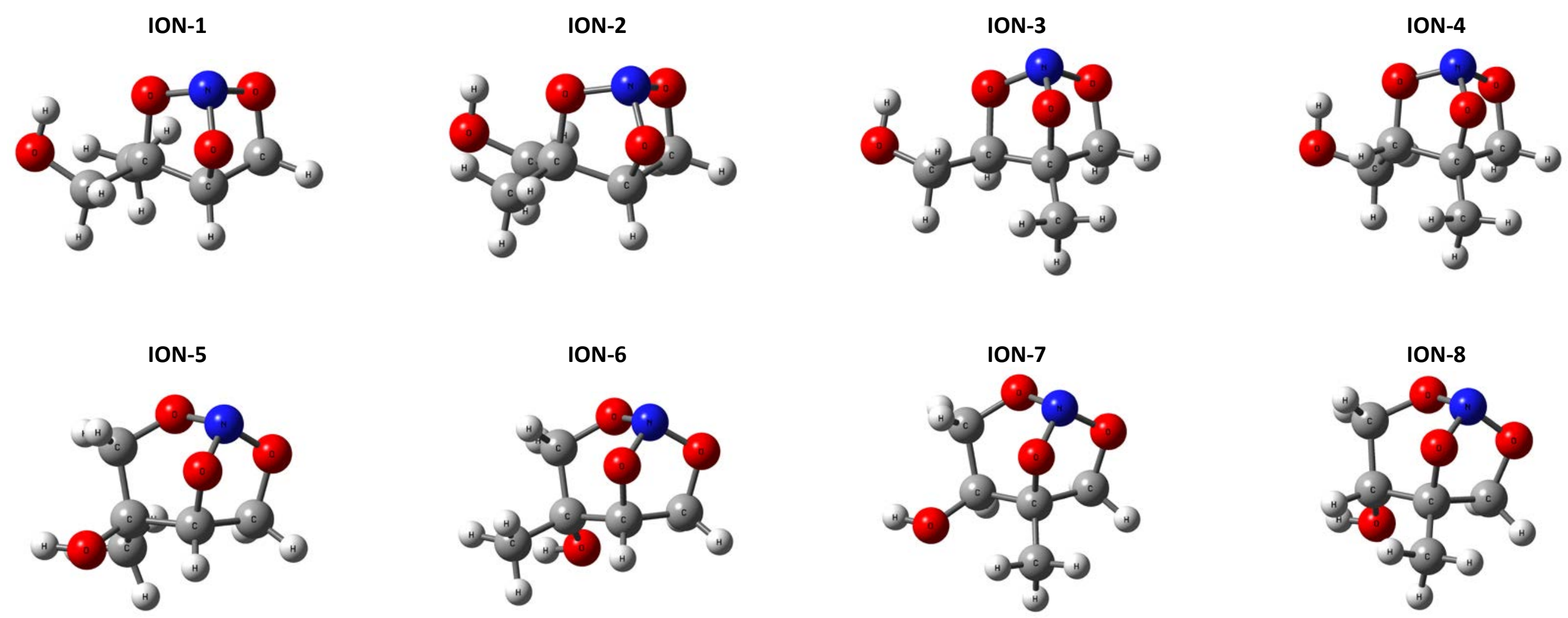

Figure 2. Optimized structures for the isoprene orthonitrite (ION) isomers, calculated at the M06-2X/6-31G(2df,p) level of theory. 
TS1
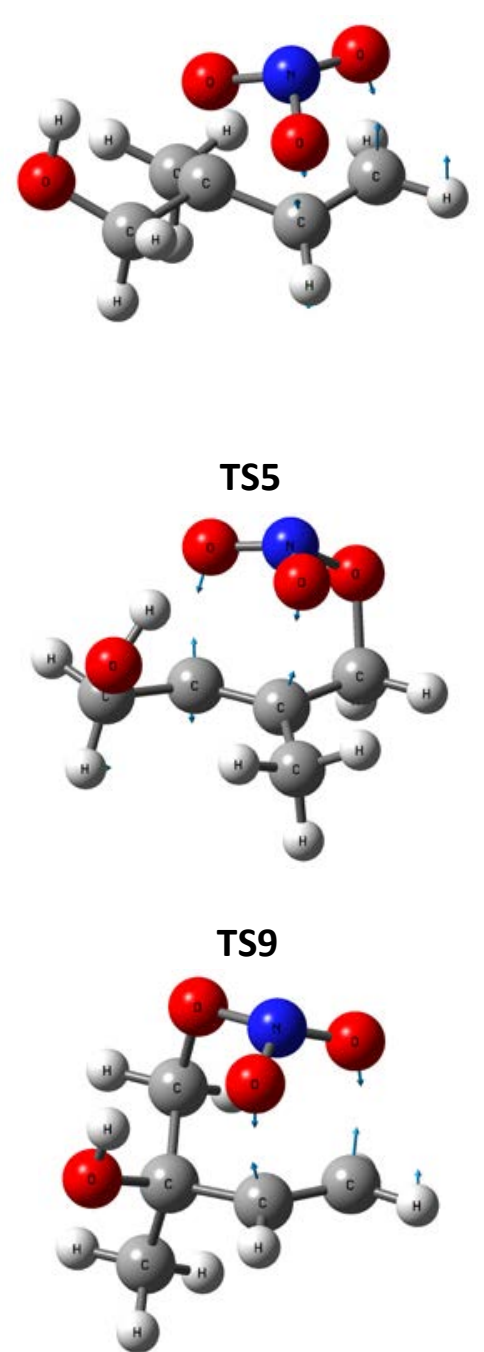

TS2

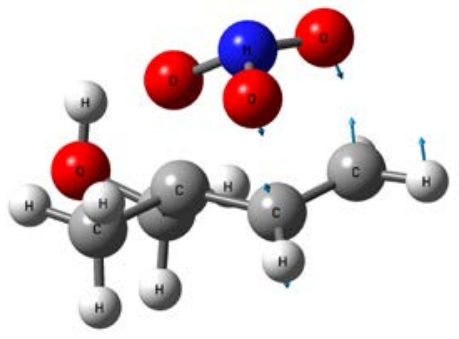

TS6

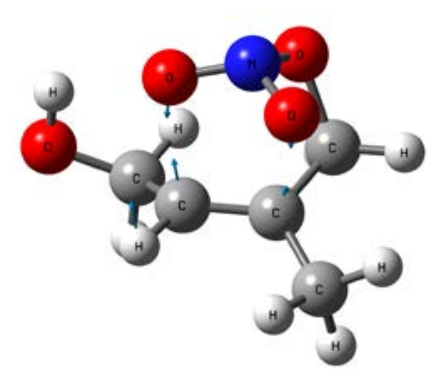

TS10

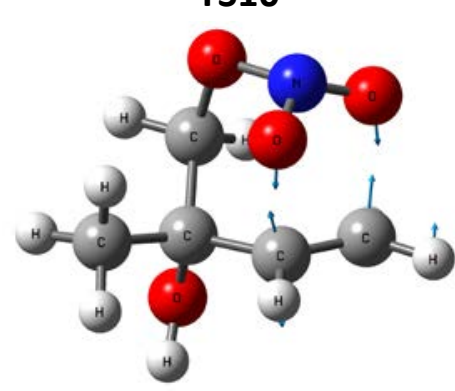

TS3
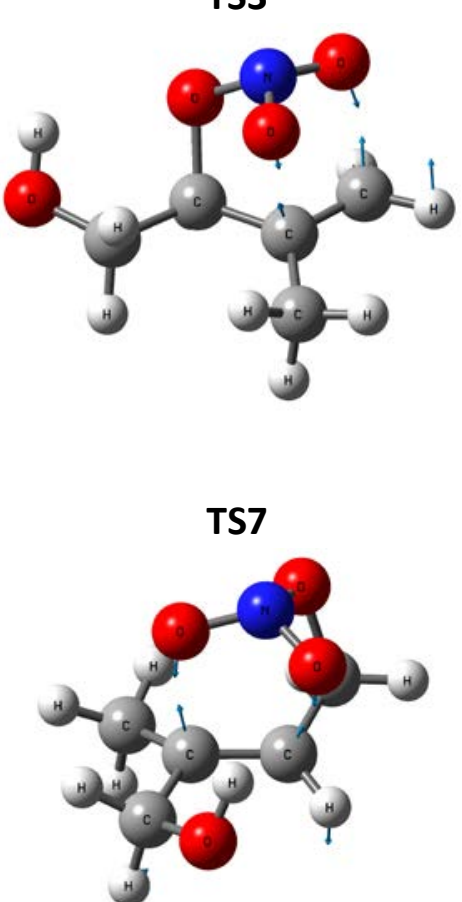

TS11

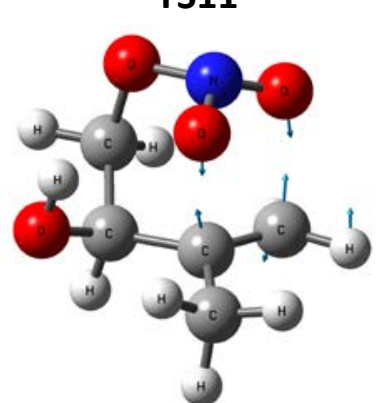

TS4

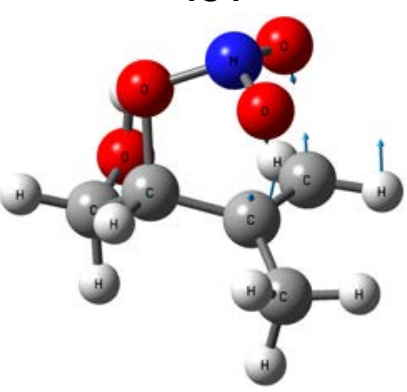

TS8

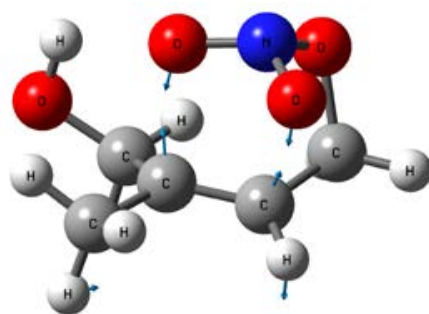

TS12

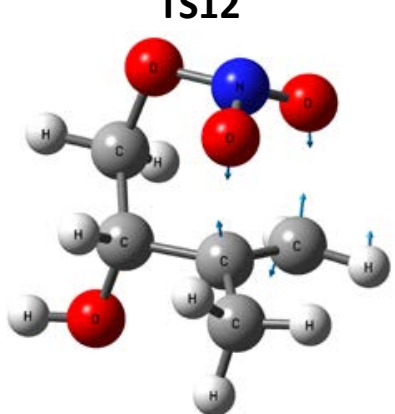

Figure 3. Optimized transition state structures for isomerization of the isoprene hydroxy nitrates to orthonitrites, calculated at the M06-2X/6$31 \mathrm{G}(2 \mathrm{df}, \mathrm{p})$ level of theory. Displacement vectors for imaginary frequencies are indicated. 


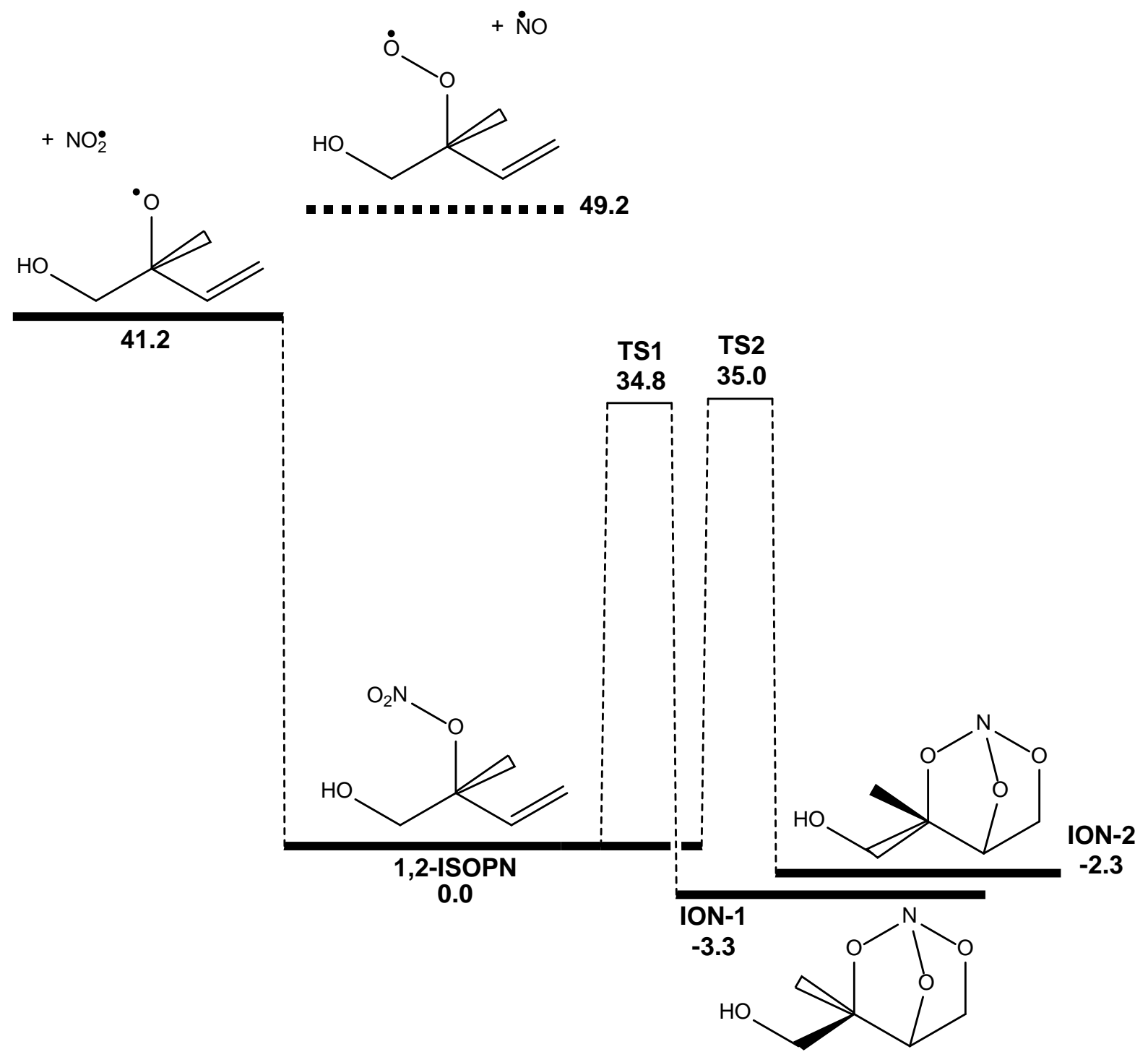

Figure 4. Potential energy diagram for isomerization of 1,2-ISOPN to the isoprene orthonitrites ION-1 and ION-2. The initiating peroxyl radical + NO energy (dashed line) is included for reference. Energies are $0 \mathrm{~K}$ enthalpies in $\mathrm{kcal} \mathrm{mol}^{-1}$ at the $\mathrm{G} 3 \mathrm{X}-\mathrm{K}$ level of theory. 


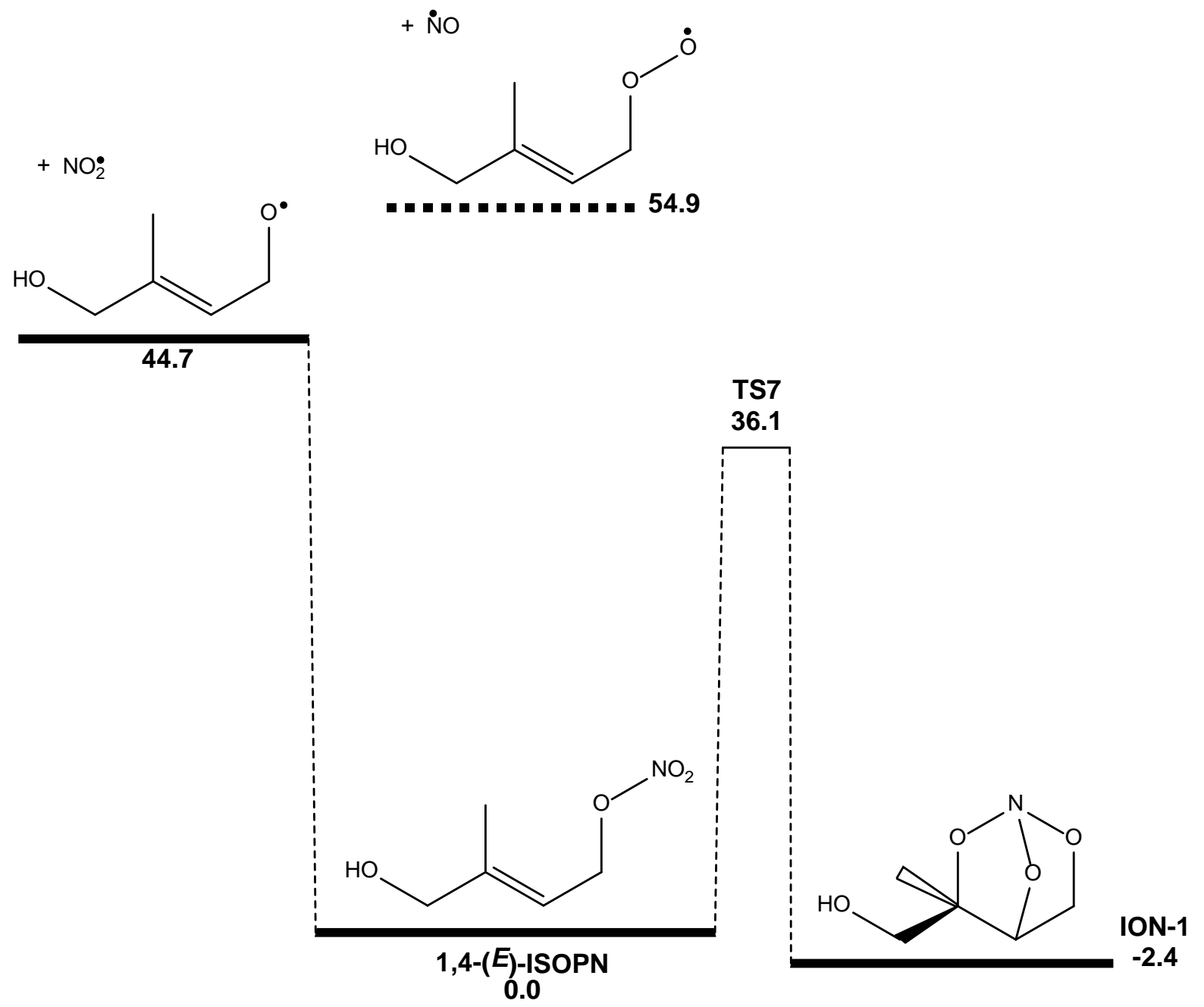

Figure 5. Potential energy diagram for isomerization of 1,4-(E)-ISOPN to the isoprene orthonitrite ION-3. The initiating peroxyl radical + NO energy (dashed line) is included for reference. Energies are $0 \mathrm{~K}$ enthalpies in $\mathrm{kcal} \mathrm{mol}^{-1}$ at the $\mathrm{G} 3 \mathrm{X}-\mathrm{K}$ level of theory. 


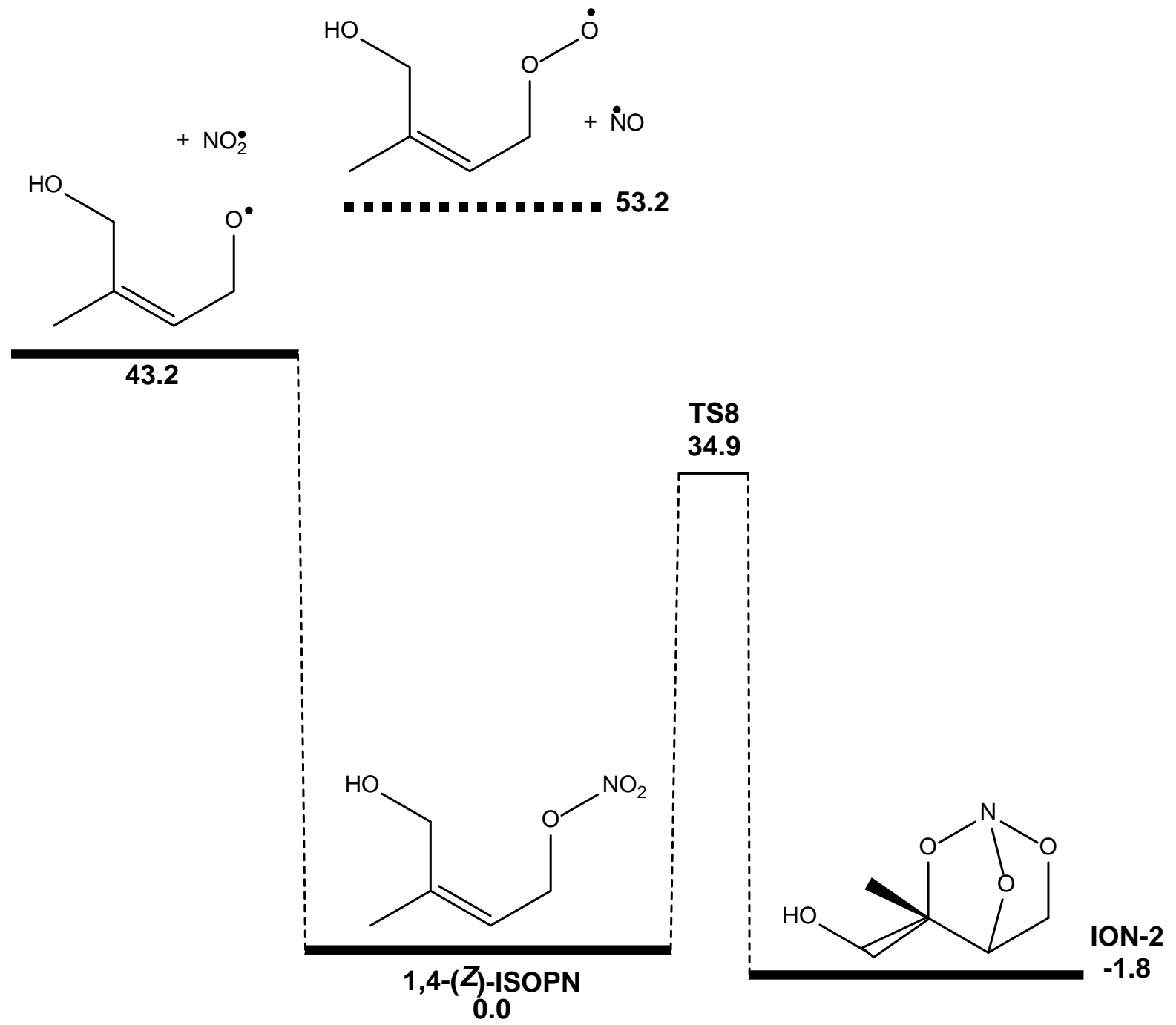

Figure 6. Potential energy diagram for isomerization of 4,1-(Z)-ISOPN to the isoprene orthonitrite ION-4. The initiating peroxyl radical + NO energy (dashed line) is included for reference. Energies are $0 \mathrm{~K}$ enthalpies in $\mathrm{kcal} \mathrm{mol}^{-1}$ at the $\mathrm{G} 3 \mathrm{X}-\mathrm{K}$ level of theory. 


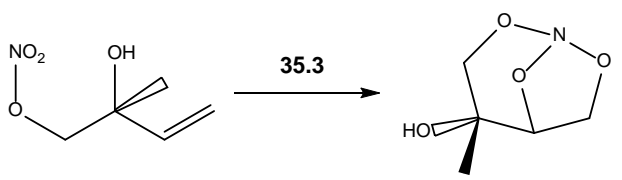

35.5<smiles>CC(O)=CCON=O</smiles>

${ }^{38.5}$

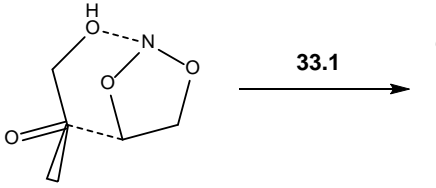

30.3

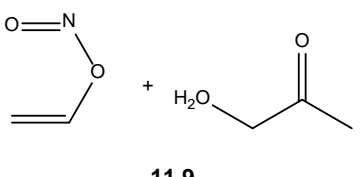

$-11.9$

Figure 7. Reaction scheme for the decomposition of the isoprene orthonitite ION-6, formed from 2,1-ISOPN. Energies are $0 \mathrm{~K}$ enthalpies in $\mathrm{kcal} \mathrm{mol}^{-1}$ at the G3X-K level of theory. 


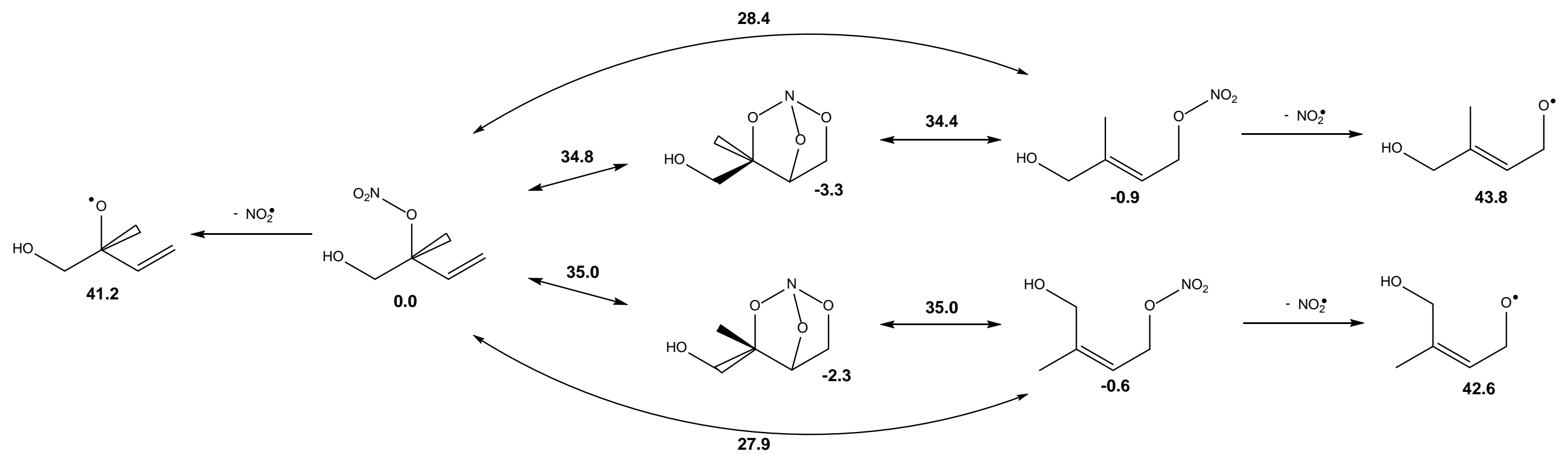

Figure 8. Reaction scheme for interconversion of the isoprene hydroxy nitrates 1,2-ISOPN, 1,4-(E)-ISOPN, and 1,4-(Z)-ISOPN and decomposition to the corresponding alkoxyl radicals. Energies are $0 \mathrm{~K}$ enthalpies in $\mathrm{kcal} \mathrm{mol}^{-1}$ at the G3X-K level of theory, relative to 1,2-ISOPN. 

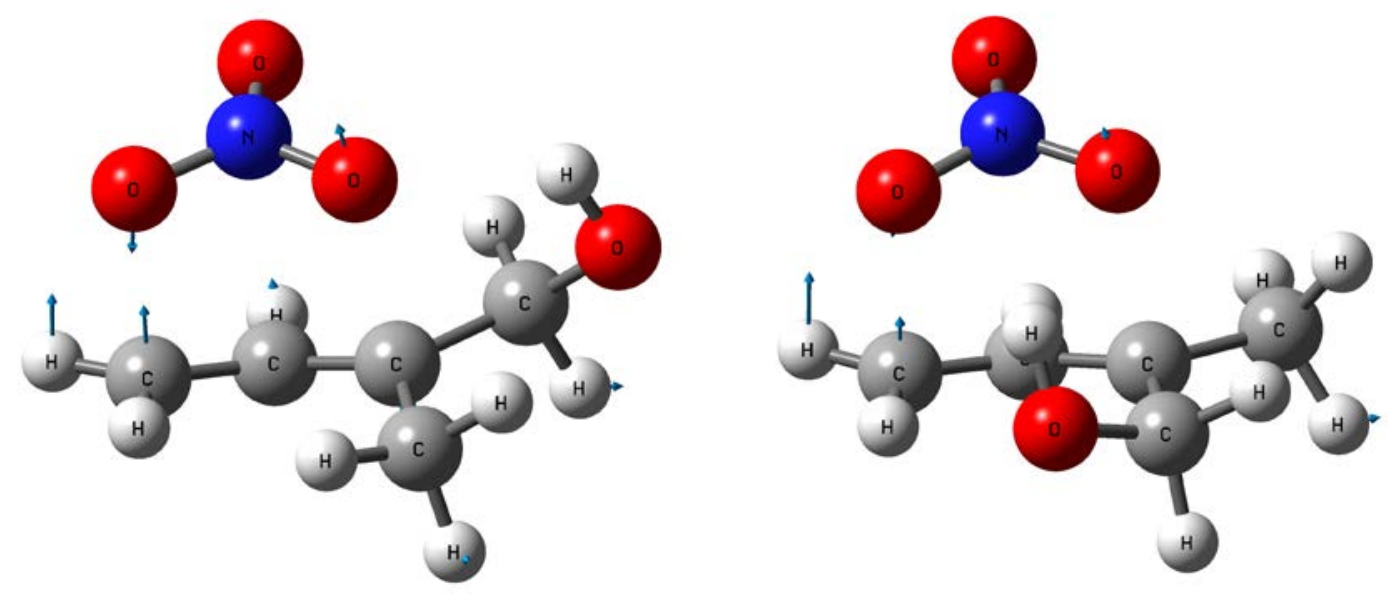

Figure 9. Optimized transition state structures for $\mathrm{NO}_{2}$ migration in 1,2-ISOPN to 1,4-(E)ISOPN (left) and 1,4-(E)-ISOPN (right), calculated at the M06-2X/6-31G(2df,p) level of theory. Displacement vectors for imaginary frequencies are indicated. 
TOC Image

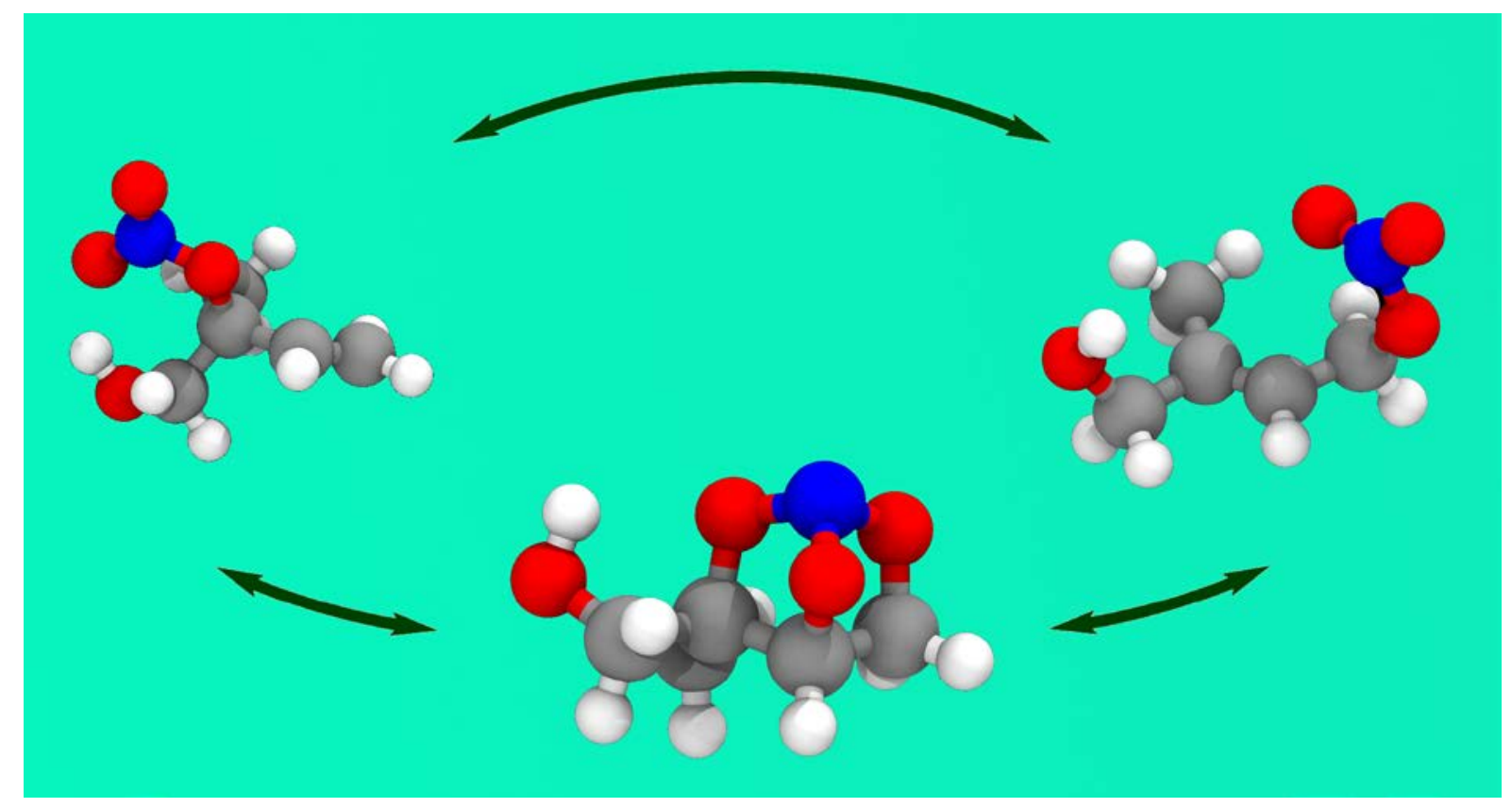


SUPPORTING INFORMATION

Isomerization of the Isoprene Hydroxy Nitrates and Formation of Orthonitrite Compounds

Gabriel da Silva*

Department of Chemical and Biomolecular Engineering, The University of Melbourne, Victoria 3010 Australia

*gdasilva@unimelb.edu.au 


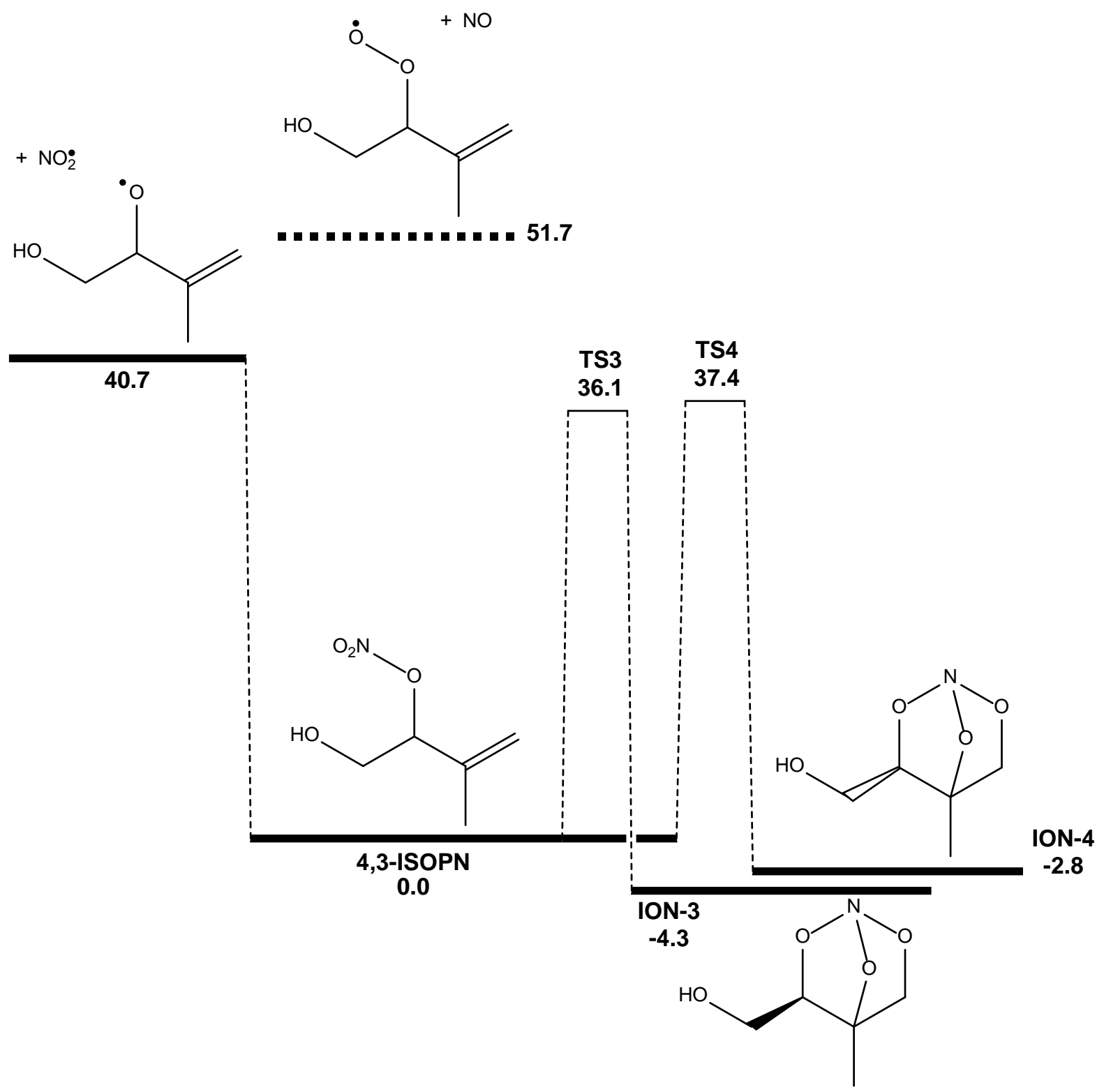

Figure S1. Potential energy diagram for isomerization of 4,3-ISOPN to the isoprene orthonitrites ION-3 and ION-4. The initiating peroxyl radical + NO energy (dashed line) is included for reference. Energies are $0 \mathrm{~K}$ enthalpies in $\mathrm{kcal} \mathrm{mol}^{-1}$ at the $\mathrm{G} 3 \mathrm{X}-\mathrm{K}$ level of theory. 


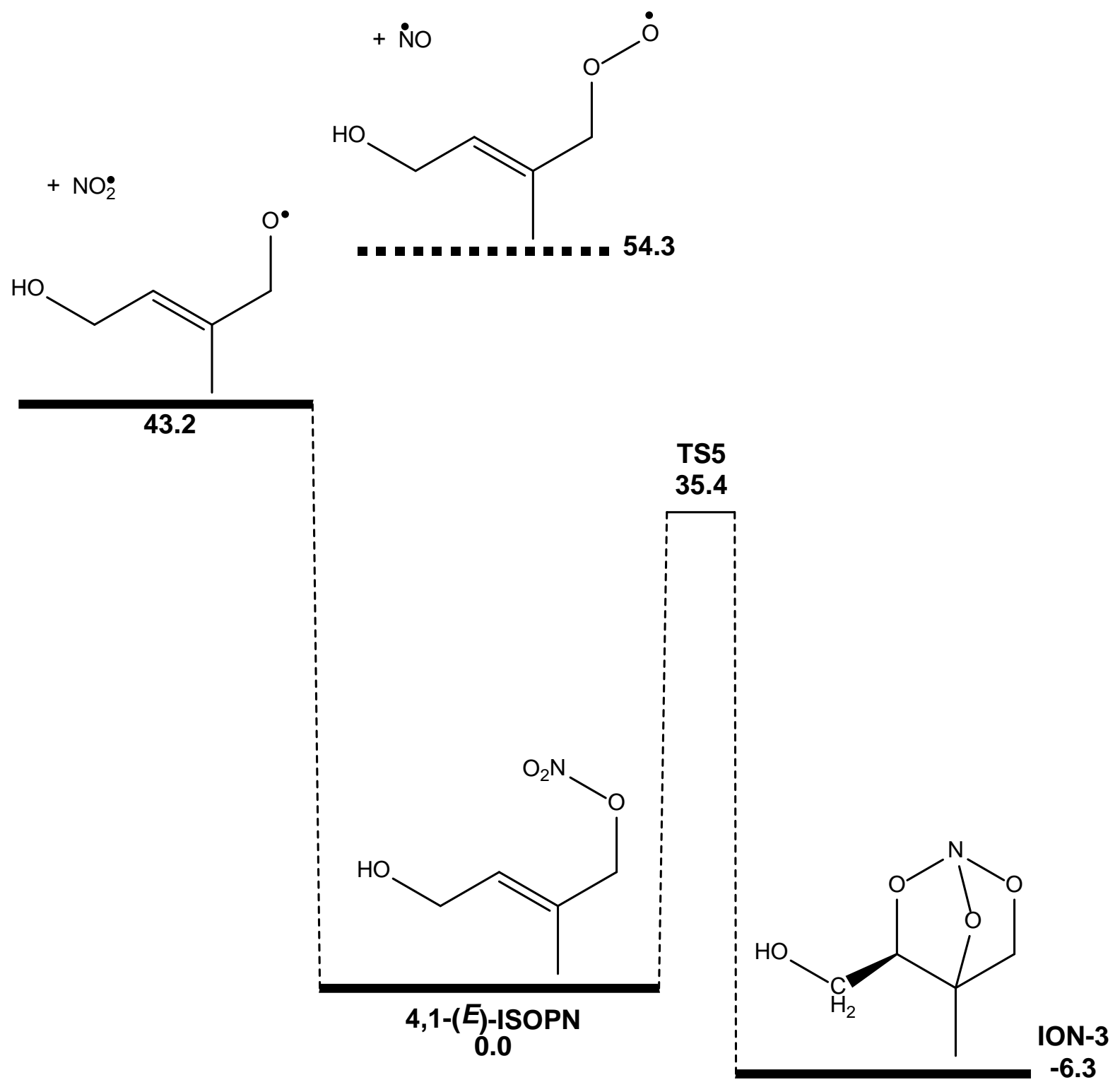

Figure S2. Potential energy diagram for isomerization of 4,1-(E)-ISOPN to the isoprene orthonitrite ION-1. The initiating peroxyl radical + NO energy (dashed line) is included for reference. Energies are $0 \mathrm{~K}$ enthalpies in $\mathrm{kcal} \mathrm{mol}^{-1}$ at the $\mathrm{G} 3 \mathrm{X}-\mathrm{K}$ level of theory. 


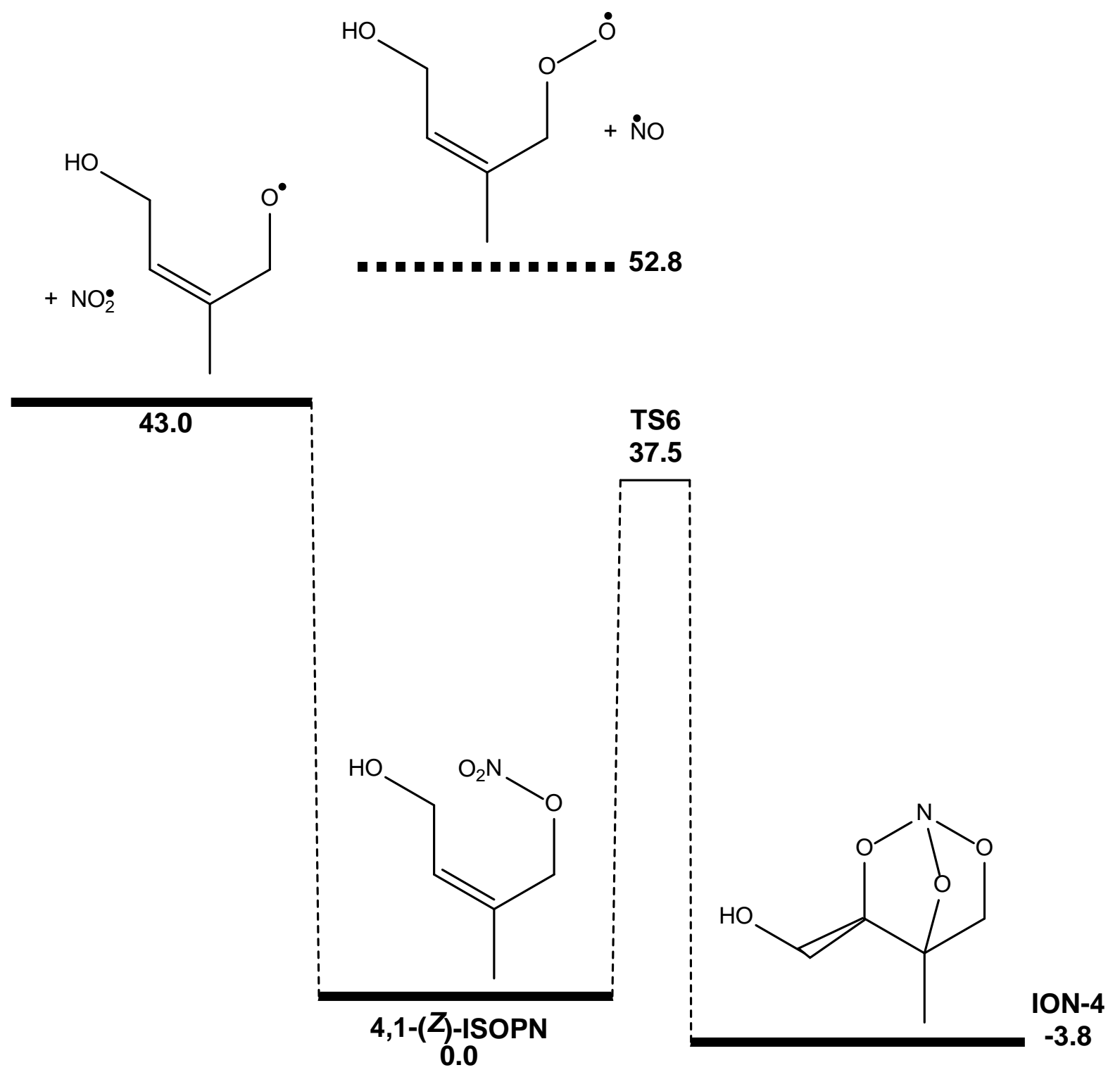

Figure S3. Potential energy diagram for isomerization of 4,1-(Z)-ISOPN to the isoprene orthonitrite ION-2. The initiating peroxyl radical + NO energy (dashed line) is included for reference. Energies are $0 \mathrm{~K}$ enthalpies in $\mathrm{kcal} \mathrm{mol}^{-1}$ at the $\mathrm{G} 3 \mathrm{X}-\mathrm{K}$ level of theory. 


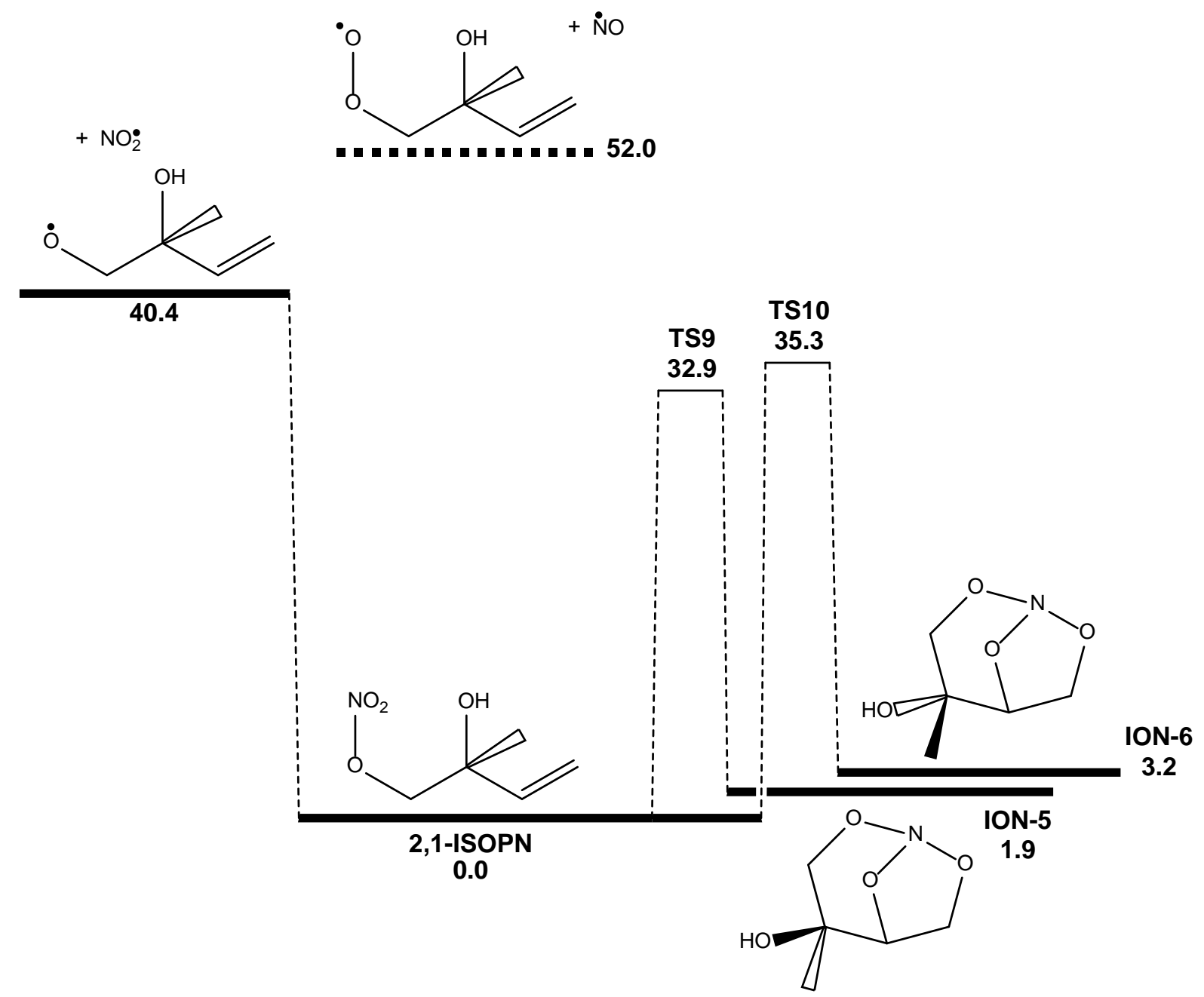

Figure S4. Potential energy diagram for isomerization of 2,1-ISOPN to the isoprene orthonitrites ION-5 and ION-6. The initiating peroxyl radical + NO energy (dashed line) is included for reference. Energies are $0 \mathrm{~K}$ enthalpies in $\mathrm{kcal} \mathrm{mol}^{-1}$ at the $\mathrm{G} 3 \mathrm{X}-\mathrm{K}$ level of theory. 


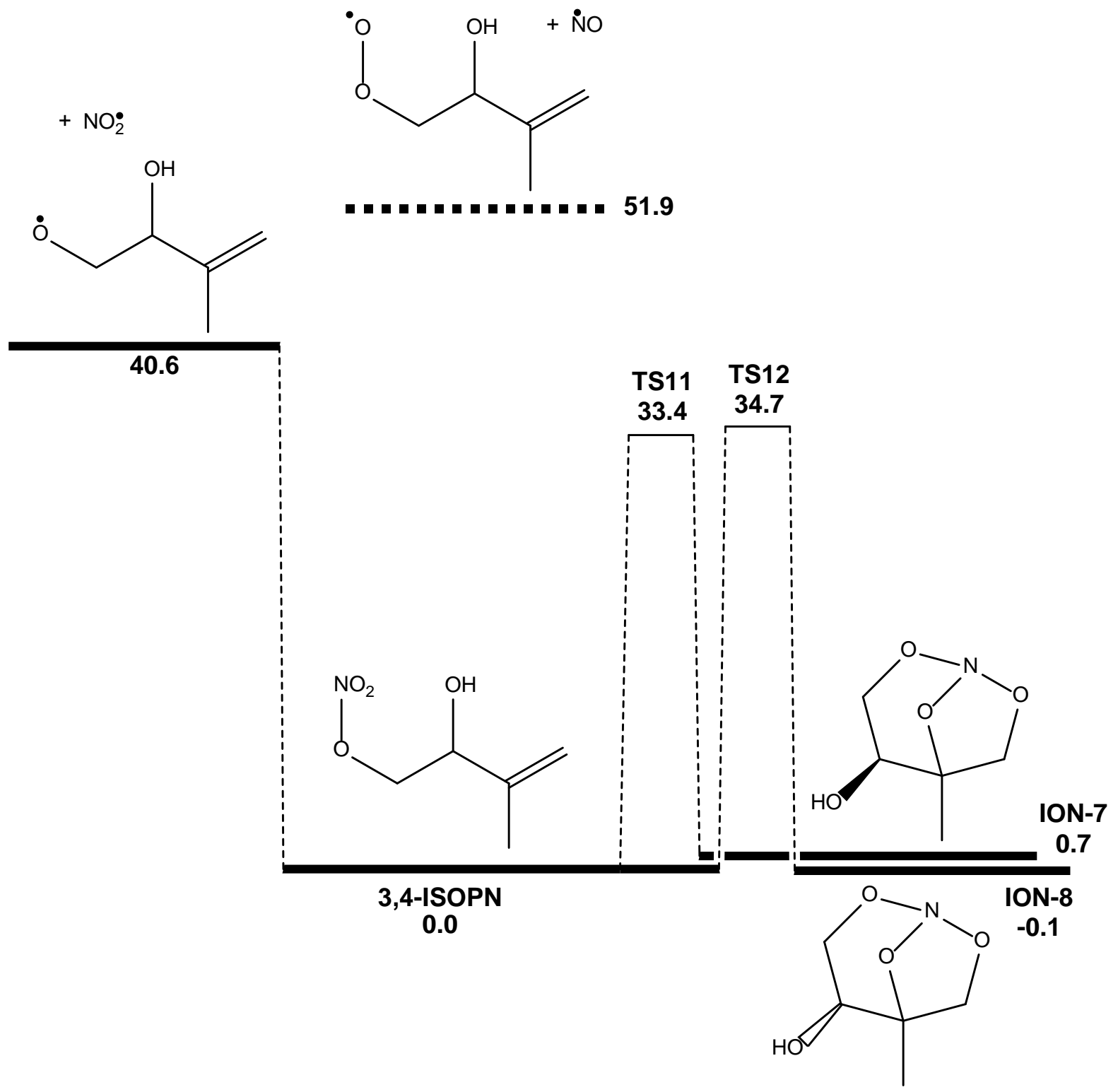

Figure S5. Potential energy diagram for isomerization of 3,4-ISOPN to the isoprene orthonitrites ION-7 and ION-8. The initiating peroxyl radical + NO energy (dashed line) is included for reference. Energies are $0 \mathrm{~K}$ enthalpies in $\mathrm{kcal} \mathrm{mol}^{-1}$ at the $\mathrm{G} 3 \mathrm{X}-\mathrm{K}$ level of theory. 


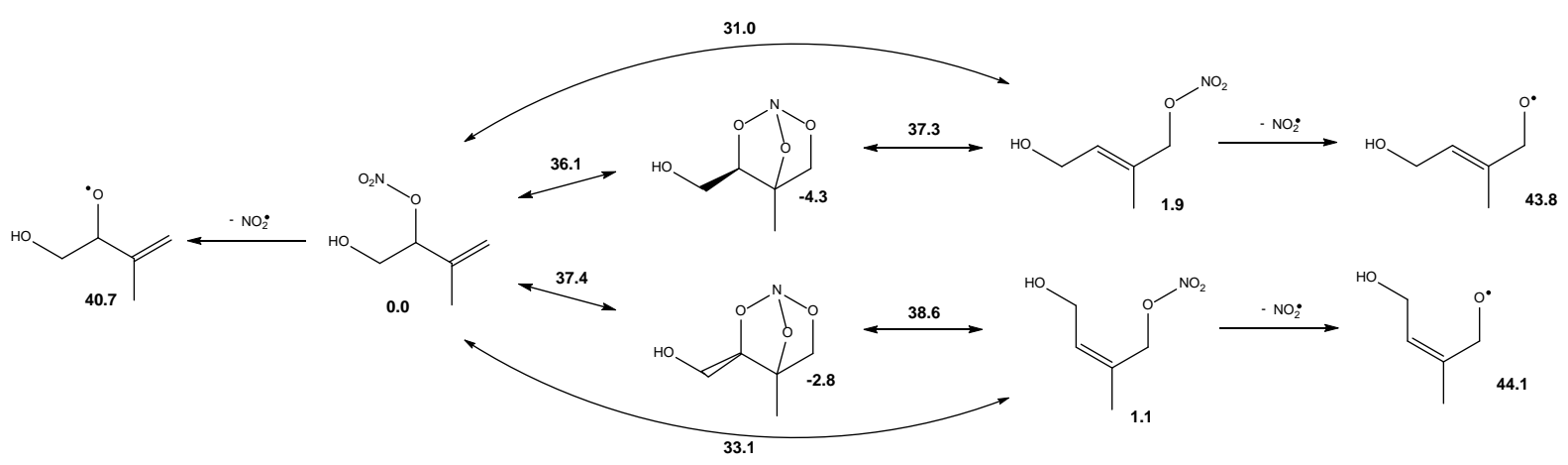

Figure S6. Reaction scheme for the decomposition of the isoprene orthonitite ION-6, formed from 2,1-ISOPN. Energies are $0 \mathrm{~K}$ enthalpies in $\mathrm{kcal} \mathrm{mol}^{-1}$ at the G3X-K level of theory. 


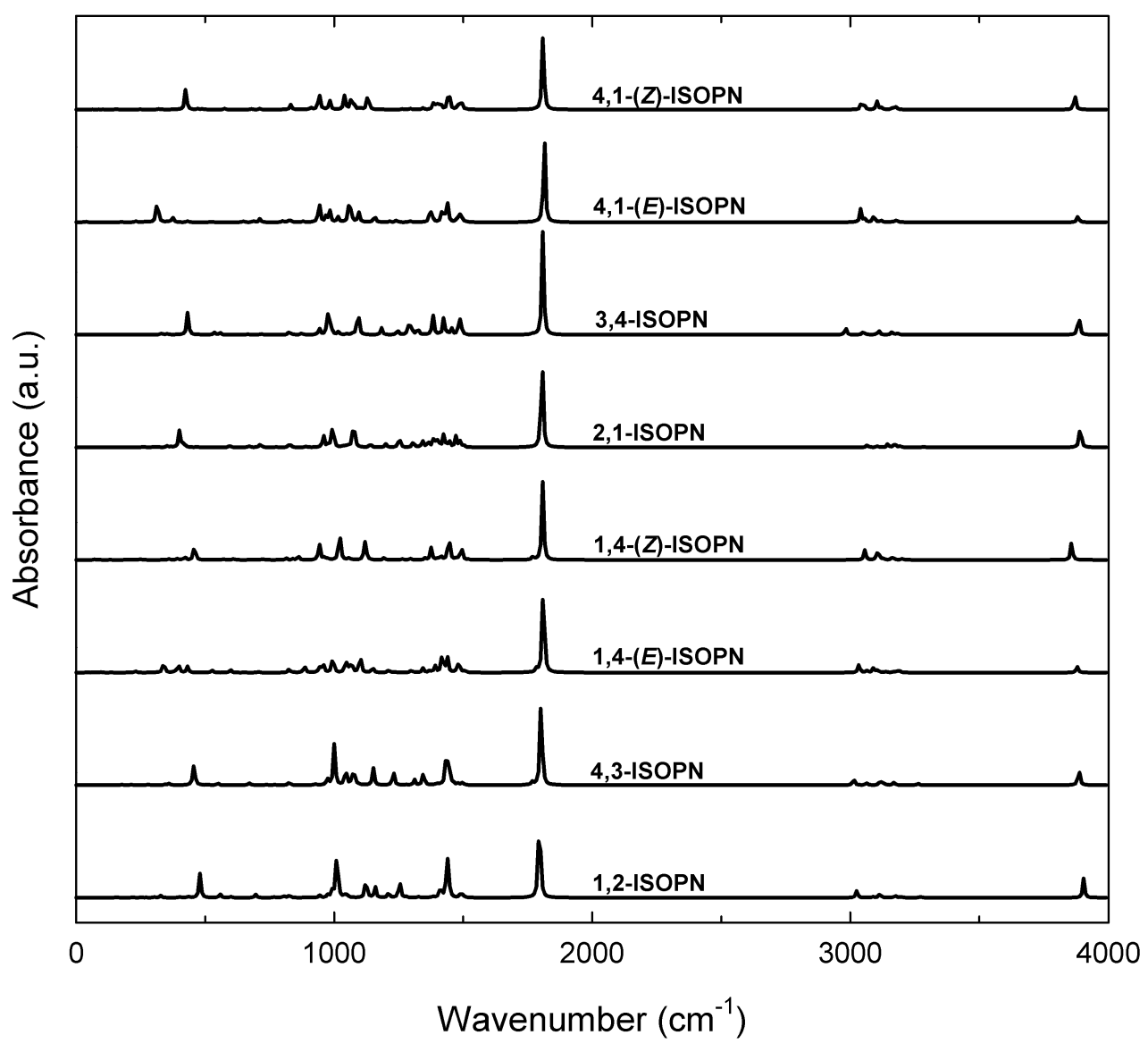

Figure S7. Predicted IR spectra for the isoprene nitrates (ISOPNs), at the M06-2X/6$31 G(2 d f, p)$ level of theory. 


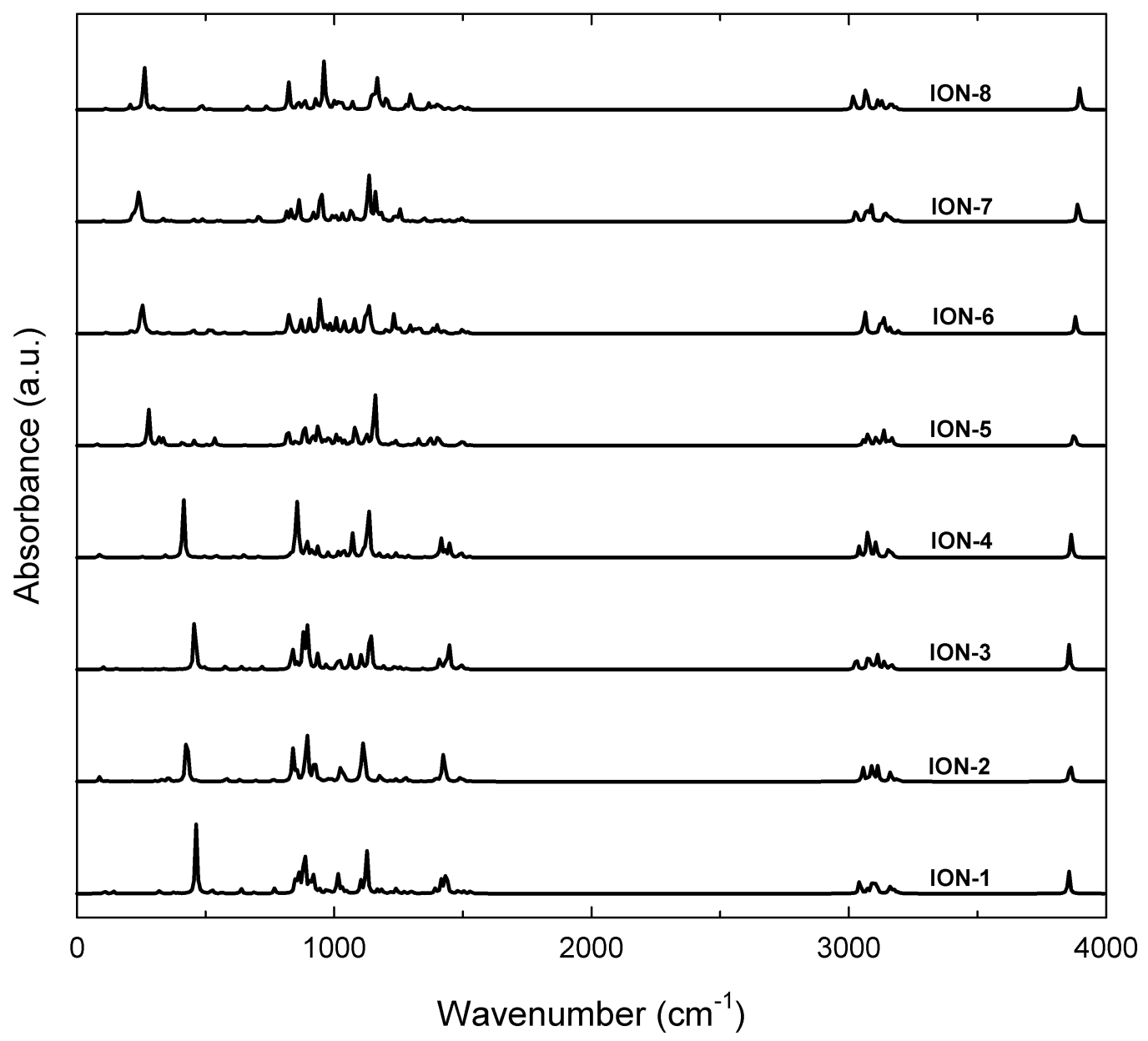

Figure S8. Predicted IR spectra for the isoprene orthonitrites (IONs), at the M06-2X/6$31 G(2 d f, p)$ level of theory. 
Cartesian coordinates (in Å)

\begin{tabular}{cccc}
$\begin{array}{l}\text { 1,2- } \\
\text { ISOPN }\end{array}$ & & & \\
\hline C & 0.50111 & 1.28427 & -0.84545 \\
C & 0.64527 & -0.01268 & -0.00333 \\
O & -0.44594 & -0.97163 & -0.25230 \\
O & 0.03818 & 2.40523 & -0.15753 \\
N & -1.73291 & -0.59170 & -0.01543 \\
O & -2.51687 & -1.47860 & -0.14048 \\
O & -1.96001 & 0.55779 & 0.27822 \\
H & -0.10207 & 1.04453 & -1.73373 \\
H & -0.87712 & 2.23601 & 0.08057 \\
C & 1.79439 & -0.80425 & -0.58089 \\
H & 1.64756 & -1.09934 & -1.61773 \\
C & 2.91914 & -1.10509 & 0.04690 \\
H & 3.10056 & -0.82908 & 1.07926 \\
H & 3.71127 & -1.64272 & -0.46007 \\
H & 1.50550 & 1.54249 & -1.19229 \\
C & 0.77180 & 0.26432 & 1.48176 \\
H & 0.92210 & -0.66962 & 2.02634 \\
H & 1.62388 & 0.92611 & 1.65014 \\
H & -0.11438 & 0.77183 & 1.85835 \\
\hline
\end{tabular}

1,4-(E)-ISOPN

\begin{tabular}{llll}
\hline $\mathrm{C}$ & -0.39527 & 0.92761 & -0.64471 \\
$\mathrm{C}$ & 0.87022 & 1.46351 & -0.05826 \\
$\mathrm{H}$ & 0.86536 & 1.48959 & 1.03041 \\
$\mathrm{H}$ & 1.08918 & 2.46475 & -0.43720 \\
$\mathrm{C}$ & -1.45036 & 0.47783 & 0.03245 \\
$\mathrm{O}$ & 1.42170 & -0.80108 & 0.96503 \\
$\mathrm{~N}$ & 2.15734 & -0.51828 & 0.05904 \\
$\mathrm{O}$ & 2.01968 & 0.72431 & -0.51990 \\
$\mathrm{O}$ & 3.02991 & -1.16651 & -0.42938 \\
$\mathrm{C}$ & -2.66853 & -0.00591 & -0.71882 \\
$\mathrm{H}$ & -3.54081 & 0.59246 & -0.43201 \\
$\mathrm{H}$ & -2.51896 & 0.11953 & -1.79968 \\
$\mathrm{O}$ & -2.99895 & -1.33791 & -0.38816 \\
$\mathrm{H}$ & -2.24305 & -1.88737 & -0.61332 \\
$\mathrm{C}$ & -1.56468 & 0.38672 & 1.52682 \\
$\mathrm{H}$ & -2.18450 & 1.20488 & 1.90972 \\
$\mathrm{H}$ & -2.06938 & -0.54688 & 1.78561 \\
$\mathrm{H}$ & -0.59918 & 0.41059 & 2.03013 \\
$\mathrm{H}$ & -0.42693 & 0.93135 & -1.73253 \\
\hline
\end{tabular}

\section{1,4-(Z)-ISOPN}

\begin{tabular}{llll}
\hline $\mathrm{C}$ & 0.58022 & -1.39422 & 0.13121 \\
$\mathrm{C}$ & -0.56593 & -1.23778 & 1.09099 \\
$\mathrm{H}$ & -0.25594 & -1.18568 & 2.13687 \\
$\mathrm{H}$ & -1.30438 & -2.03124 & 0.97914 \\
$\mathrm{C}$ & 1.53588 & -0.47803 & -0.02206 \\
$\mathrm{O}$ & -1.97978 & 1.33278 & -0.62051 \\
$\mathrm{~N}$ & -1.80279 & 0.18730 & -0.32210 \\
$\mathrm{O}$ & -1.21454 & 0.04370 & 0.91652 \\
$\mathrm{O}$ & -2.06853 & -0.80351 & -0.93521 \\
$\mathrm{C}$ & 1.59183 & 0.79782 & 0.79417 \\
$\mathrm{H}$ & 1.06599 & 0.68459 & 1.74947 \\
$\mathrm{H}$ & 2.63931 & 1.02302 & 1.02213 \\
$\mathrm{O}$ & 1.10628 & 1.90087 & 0.06183 \\
$\mathrm{H}$ & 0.14455 & 1.84654 & 0.04027 \\
$\mathrm{C}$ & 2.59303 & -0.58552 & -1.07906 \\
$\mathrm{H}$ & 2.45189 & -1.45928 & -1.71684 \\
$\mathrm{H}$ & 2.57072 & 0.31654 & -1.69861 \\
$\mathrm{H}$ & 3.58799 & -0.63715 & -0.62444 \\
$\mathrm{H}$ & 0.56164 & -2.27272 & -0.50584 \\
\hline
\end{tabular}

2,1-

ISOPN

\begin{tabular}{llll}
\hline $\mathrm{C}$ & -2.36377 & -0.55263 & -0.21816 \\
$\mathrm{H}$ & -2.46681 & -1.63259 & -0.30382 \\
$\mathrm{C}$ & -3.38292 & 0.25008 & -0.47724 \\
$\mathrm{H}$ & -3.27825 & 1.32394 & -0.38604 \\
$\mathrm{H}$ & -4.34635 & -0.14477 & -0.77703 \\
$\mathrm{C}$ & -0.99391 & -0.08022 & 0.21025 \\
$\mathrm{C}$ & -0.03120 & -0.43266 & -0.95053 \\
$\mathrm{H}$ & -0.38150 & -1.31754 & -1.48391 \\
$\mathrm{H}$ & 0.03161 & 0.41178 & -1.63987 \\
$\mathrm{O}$ & 1.28927 & -0.86069 & -0.56574 \\
$\mathrm{O}$ & -1.07598 & 1.30830 & 0.40902 \\
$\mathrm{~N}$ & 2.13687 & 0.12311 & -0.13760 \\
$\mathrm{O}$ & 3.23108 & -0.26854 & 0.11333 \\
$\mathrm{O}$ & 1.70759 & 1.24871 & -0.06178 \\
$\mathrm{H}$ & -0.18282 & 1.63878 & 0.53943 \\
$\mathrm{C}$ & -0.57977 & -0.79588 & 1.49959 \\
$\mathrm{H}$ & -0.50203 & -1.87627 & 1.35233 \\
$\mathrm{H}$ & 0.38873 & -0.42920 & 1.85245 \\
$\mathrm{H}$ & -1.32695 & -0.59033 & 2.26754 \\
\hline
\end{tabular}




\begin{tabular}{lccc}
\multicolumn{4}{l}{ 4,1-(E)-ISOPN } \\
\hline $\mathrm{C}$ & 0.63773 & 0.76214 & -0.29197 \\
$\mathrm{C}$ & -0.69187 & 1.10138 & -0.90629 \\
$\mathrm{H}$ & -0.85495 & 0.58978 & -1.85496 \\
$\mathrm{H}$ & -0.79654 & 2.18108 & -1.04751 \\
$\mathrm{C}$ & 1.44582 & -0.09537 & -0.91252 \\
$\mathrm{O}$ & -1.55082 & -1.28636 & -0.64113 \\
$\mathrm{~N}$ & -2.09699 & -0.51862 & 0.10136 \\
$\mathrm{O}$ & -1.78453 & 0.82185 & -0.00954 \\
$\mathrm{O}$ & -2.90825 & -0.73693 & 0.94655 \\
$\mathrm{C}$ & 2.80601 & -0.52742 & -0.41752 \\
$\mathrm{H}$ & 3.19907 & -1.30854 & -1.08099 \\
$\mathrm{H}$ & 3.51073 & 0.31029 & -0.45994 \\
$\mathrm{O}$ & 2.80927 & -0.96277 & 0.92736 \\
$\mathrm{H}$ & 2.08905 & -1.59107 & 1.02774 \\
$\mathrm{H}$ & 1.10298 & -0.54304 & -1.84238 \\
$\mathrm{C}$ & 0.94805 & 1.47607 & 0.99355 \\
$\mathrm{H}$ & 1.89364 & 1.14810 & 1.42018 \\
$\mathrm{H}$ & 0.97844 & 2.55811 & 0.82244 \\
$\mathrm{H}$ & 0.15663 & 1.29853 & 1.72849 \\
\hline
\end{tabular}

\begin{tabular}{cccc} 
3,4-ISOPN & & & \\
\hline C & 2.15578 & -0.16645 & -0.11247 \\
C & 3.11057 & 0.65199 & 0.30703 \\
H & 2.90190 & 1.69452 & 0.50858 \\
H & 4.12779 & 0.30026 & 0.43980 \\
C & 0.73013 & 0.31026 & -0.27814 \\
C & -0.12845 & -0.24274 & 0.88329 \\
H & 0.38225 & -1.03664 & 1.42858 \\
H & -0.37091 & 0.57134 & 1.56970 \\
O & -1.32823 & -0.91516 & 0.46527 \\
O & 0.70692 & 1.70857 & -0.31497 \\
N & -2.30343 & -0.09736 & -0.04042 \\
O & -3.29149 & -0.67614 & -0.35962 \\
O & -2.07224 & 1.08553 & -0.10446 \\
H & -0.21441 & 1.97710 & -0.37362 \\
H & 0.32723 & -0.12651 & -1.20862 \\
C & 2.38667 & -1.61097 & -0.45281 \\
H & 3.40101 & -1.91914 & -0.19627 \\
H & 1.68643 & -2.27407 & 0.06792 \\
H & 2.23476 & -1.78032 & -1.52431 \\
\hline
\end{tabular}

\begin{tabular}{lccc}
\multicolumn{4}{l}{ 4,1-(Z)-ISOPN } \\
\hline $\mathrm{C}$ & 1.32619 & -0.57656 & 0.05720 \\
$\mathrm{C}$ & 0.35679 & -0.82988 & 1.19062 \\
$\mathrm{H}$ & 0.70900 & -0.44219 & 2.14907 \\
$\mathrm{H}$ & 0.13213 & -1.89241 & 1.29796 \\
$\mathrm{C}$ & 1.58000 & 0.66321 & -0.35867 \\
$\mathrm{O}$ & -2.40091 & 0.29802 & -0.44684 \\
$\mathrm{~N}$ & -1.58224 & -0.50337 & -0.10538 \\
$\mathrm{O}$ & -0.87251 & -0.10000 & 1.00664 \\
$\mathrm{O}$ & -1.32133 & -1.56880 & -0.58200 \\
$\mathrm{C}$ & 1.02878 & 1.93275 & 0.24529 \\
$\mathrm{H}$ & 0.77610 & 1.77767 & 1.30216 \\
$\mathrm{H}$ & 1.80762 & 2.70041 & 0.21239 \\
$\mathrm{O}$ & -0.06444 & 2.45883 & -0.47297 \\
$\mathrm{H}$ & -0.84270 & 1.93090 & -0.26802 \\
$\mathrm{H}$ & 2.22722 & 0.79140 & -1.22343 \\
$\mathrm{C}$ & 1.92604 & -1.80179 & -0.56818 \\
$\mathrm{H}$ & 2.60781 & -1.53756 & -1.37755 \\
$\mathrm{H}$ & 2.48611 & -2.38379 & 0.17213 \\
$\mathrm{H}$ & 1.13912 & -2.45165 & -0.96321 \\
\hline
\end{tabular}

\begin{tabular}{cccc} 
4,3-ISOPN & & & \\
\hline C & 0.22687 & 1.39797 & -0.72622 \\
C & 0.41426 & 0.23098 & 0.26962 \\
O & -0.44893 & -0.89726 & -0.04000 \\
O & -0.39101 & 2.51693 & -0.16233 \\
N & -1.78749 & -0.68505 & 0.12741 \\
O & -2.45578 & -1.63776 & -0.12005 \\
O & -2.14786 & 0.40406 & 0.50330 \\
H & -0.30429 & 1.01618 & -1.61181 \\
H & -1.27210 & 2.24727 & 0.11176 \\
C & 1.79925 & -0.35956 & 0.22046 \\
C & 2.61044 & -0.23326 & 1.26215 \\
H & 2.28952 & 0.24492 & 2.18082 \\
H & 3.63036 & -0.60000 & 1.22711 \\
H & 1.21497 & 1.73226 & -1.05449 \\
H & 0.17692 & 0.58945 & 1.27395 \\
C & 2.19295 & -1.02496 & -1.06794 \\
H & 3.23457 & -1.34649 & -1.03712 \\
H & 1.56182 & -1.89686 & -1.25938 \\
H & 2.06675 & -0.34612 & -1.91846 \\
\hline
\end{tabular}


ION-1

\begin{tabular}{llll}
\hline C & -0.66173 & 0.15478 & 1.03285 \\
H & -0.50999 & 0.27135 & 2.10303 \\
C & -1.88075 & 0.81655 & 0.41157 \\
H & -1.73401 & 1.86048 & 0.13469 \\
H & -2.76816 & 0.70865 & 1.04038 \\
C & 0.56153 & 0.36254 & 0.13347 \\
C & 1.81212 & -0.29671 & 0.71980 \\
H & 2.24316 & 0.34968 & 1.49164 \\
H & 1.52707 & -1.25205 & 1.17993 \\
O & 0.15657 & -0.45371 & -1.00112 \\
O & 2.78917 & -0.46733 & -0.27225 \\
N & -1.08255 & -1.03681 & -0.66510 \\
O & -2.02640 & 0.01223 & -0.77038 \\
O & -0.96923 & -1.20776 & 0.70869 \\
H & 2.37603 & -0.98961 & -0.96869 \\
C & 0.84482 & 1.77590 & -0.34086 \\
H & 0.06502 & 2.12463 & -1.01891 \\
H & 0.92516 & 2.46092 & 0.50830 \\
H & 1.79678 & 1.77780 & -0.87506 \\
\hline
\end{tabular}

ION-2

\begin{tabular}{llll}
\hline $\mathrm{C}$ & 0.74587 & 0.42395 & 0.95320 \\
$\mathrm{H}$ & 0.75041 & 0.99056 & 1.88012 \\
$\mathrm{C}$ & 1.47141 & -0.90961 & 0.93260 \\
$\mathrm{H}$ & 0.89861 & -1.75470 & 1.31399 \\
$\mathrm{H}$ & 2.43612 & -0.84624 & 1.44335 \\
$\mathrm{C}$ & -0.59700 & 0.33284 & 0.21028 \\
$\mathrm{C}$ & -1.37055 & 1.63900 & 0.27143 \\
$\mathrm{H}$ & -1.78538 & 1.78926 & 1.27218 \\
$\mathrm{H}$ & -0.71068 & 2.47124 & 0.02176 \\
$\mathrm{O}$ & -0.10112 & 0.15173 & -1.14660 \\
$\mathrm{~N}$ & 1.30158 & 0.17843 & -1.07555 \\
$\mathrm{O}$ & 1.67517 & -1.05766 & -0.48045 \\
$\mathrm{O}$ & 1.52442 & 1.08982 & -0.05242 \\
$\mathrm{C}$ & -1.48167 & -0.87270 & 0.51826 \\
$\mathrm{H}$ & -0.89996 & -1.79421 & 0.39805 \\
$\mathrm{H}$ & -1.85046 & -0.82029 & 1.54812 \\
$\mathrm{O}$ & -2.60873 & -0.88620 & -0.32073 \\
$\mathrm{H}$ & -2.27907 & -0.95414 & -1.22299 \\
$\mathrm{H}$ & -2.19694 & 1.60713 & -0.43886 \\
\hline
\end{tabular}

ION-3

\begin{tabular}{cccc}
\hline $\mathrm{C}$ & -0.61603 & 0.73662 & -0.05390 \\
$\mathrm{C}$ & -1.78690 & 0.12366 & -0.82270 \\
$\mathrm{H}$ & -1.61997 & 0.08903 & -1.90188 \\
$\mathrm{H}$ & -2.73333 & 0.62353 & -0.59650 \\
$\mathrm{C}$ & 0.65535 & 0.04179 & -0.54635 \\
$\mathrm{C}$ & 1.95318 & 0.53424 & 0.07244 \\
$\mathrm{H}$ & 2.23809 & 1.49722 & -0.36304 \\
$\mathrm{H}$ & 1.79704 & 0.67176 & 1.15242 \\
$\mathrm{O}$ & 0.41944 & -1.29677 & -0.06134 \\
$\mathrm{O}$ & 2.99272 & -0.36825 & -0.19601 \\
$\mathrm{~N}$ & -0.78556 & -1.25460 & 0.68339 \\
$\mathrm{O}$ & -1.80922 & -1.20392 & -0.28167 \\
$\mathrm{O}$ & -0.78178 & 0.03436 & 1.19068 \\
$\mathrm{H}$ & 2.69485 & -1.22720 & 0.12204 \\
$\mathrm{H}$ & 0.72767 & 0.01075 & -1.63788 \\
$\mathrm{C}$ & -0.60131 & 2.22752 & 0.13320 \\
$\mathrm{H}$ & -0.46496 & 2.72389 & -0.83057 \\
$\mathrm{H}$ & -1.54716 & 2.55968 & 0.56550 \\
$\mathrm{H}$ & 0.21169 & 2.52724 & 0.79684 \\
\hline
\end{tabular}

ION-4

\begin{tabular}{cccc}
\hline C & 0.76911 & 0.67142 & -0.04862 \\
C & 1.09537 & -0.01813 & 1.26988 \\
H & 0.39698 & 0.19663 & 2.08010 \\
H & 2.11951 & 0.20358 & 1.58654 \\
C & -0.66855 & 0.32054 & -0.45300 \\
O & -0.53254 & -1.08510 & -0.74276 \\
N & 0.82454 & -1.40418 & -0.52663 \\
O & 0.98954 & -1.39374 & 0.88407 \\
O & 1.46454 & -0.24185 & -0.91950 \\
C & -1.78582 & 0.49829 & 0.55802 \\
H & -1.56558 & -0.09332 & 1.45617 \\
H & -1.87404 & 1.55146 & 0.84592 \\
O & -3.01604 & 0.12271 & -0.00662 \\
H & -2.93401 & -0.80137 & -0.26319 \\
C & 1.22051 & 2.09015 & -0.24179 \\
H & 0.67111 & 2.75382 & 0.43030 \\
H & 2.28678 & 2.18226 & -0.02667 \\
H & 1.03704 & 2.40781 & -1.26997 \\
H & -0.93738 & 0.83868 & -1.38133 \\
\hline
\end{tabular}


ION-5

\begin{tabular}{llll}
$\mathrm{C}$ & -0.04219 & 0.67634 & 0.76190 \\
$\mathrm{H}$ & 0.30084 & 1.23057 & 1.63472 \\
$\mathrm{C}$ & -1.06175 & 1.43859 & -0.09382 \\
$\mathrm{H}$ & -0.65496 & 1.81366 & -1.03270 \\
$\mathrm{H}$ & -1.51925 & 2.25820 & 0.46282 \\
$\mathrm{C}$ & 1.16616 & 0.05937 & 0.03189 \\
$\mathrm{C}$ & 0.64809 & -1.30133 & -0.46038 \\
$\mathrm{H}$ & 1.20948 & -1.66495 & -1.32564 \\
$\mathrm{H}$ & 0.72144 & -2.02683 & 0.35528 \\
$\mathrm{O}$ & -0.68175 & -1.17229 & -0.92413 \\
$\mathrm{~N}$ & -1.60563 & -0.75484 & 0.11445 \\
$\mathrm{O}$ & -2.07957 & 0.46351 & -0.34252 \\
$\mathrm{O}$ & -0.85308 & -0.41181 & 1.22472 \\
$\mathrm{O}$ & 2.14955 & -0.10579 & 1.03452 \\
$\mathrm{H}$ & 2.91886 & -0.52647 & 0.64043 \\
$\mathrm{C}$ & 1.69781 & 0.90755 & -1.11517 \\
$\mathrm{H}$ & 1.86698 & 1.94167 & -0.80256 \\
$\mathrm{H}$ & 2.65312 & 0.49375 & -1.45441 \\
$\mathrm{H}$ & 1.01302 & 0.89227 & -1.96632 \\
\hline
\end{tabular}

ION-6

\begin{tabular}{cccc}
\hline $\mathrm{C}$ & -0.01455 & 0.72881 & 0.70045 \\
$\mathrm{H}$ & 0.31761 & 1.37173 & 1.51587 \\
$\mathrm{C}$ & -1.07390 & 1.38544 & -0.20106 \\
$\mathrm{H}$ & -0.70280 & 1.54694 & -1.21165 \\
$\mathrm{H}$ & -1.46617 & 2.31063 & 0.22084 \\
$\mathrm{C}$ & 1.16120 & 0.08736 & -0.05586 \\
$\mathrm{C}$ & 0.60696 & -1.26084 & -0.54831 \\
$\mathrm{H}$ & 1.09177 & -1.54836 & -1.48532 \\
$\mathrm{H}$ & 0.78433 & -2.04325 & 0.19776 \\
$\mathrm{O}$ & -0.76596 & -1.17686 & -0.86911 \\
$\mathrm{O}$ & 1.49446 & 0.95530 & -1.11946 \\
$\mathrm{~N}$ & -1.59721 & -0.76141 & 0.24295 \\
$\mathrm{O}$ & -2.14039 & 0.42753 & -0.19092 \\
$\mathrm{O}$ & -0.74779 & -0.36227 & 1.26985 \\
$\mathrm{H}$ & 2.29407 & 0.62633 & -1.53899 \\
$\mathrm{C}$ & 2.35157 & -0.12952 & 0.86862 \\
$\mathrm{H}$ & 3.12748 & -0.72166 & 0.37076 \\
$\mathrm{H}$ & 2.77885 & 0.83495 & 1.15319 \\
$\mathrm{H}$ & 2.04510 & -0.66450 & 1.77095 \\
\hline
\end{tabular}

ION-7

\begin{tabular}{cccc}
\hline $\mathrm{C}$ & -0.31094 & 0.71972 & 0.03871 \\
$\mathrm{C}$ & 0.87570 & 1.04503 & 0.97327 \\
$\mathrm{H}$ & 0.77729 & 0.57008 & 1.95270 \\
$\mathrm{H}$ & 1.02206 & 2.11978 & 1.09355 \\
$\mathrm{C}$ & -1.09242 & -0.50976 & 0.53604 \\
$\mathrm{C}$ & -0.30017 & -1.72073 & 0.02546 \\
$\mathrm{H}$ & -0.46438 & -2.61321 & 0.63347 \\
$\mathrm{H}$ & -0.62224 & -1.91936 & -1.00267 \\
$\mathrm{O}$ & 1.09146 & -1.49051 & 0.09524 \\
$\mathrm{~N}$ & 1.52352 & -0.34411 & -0.67927 \\
$\mathrm{O}$ & 2.00956 & 0.53093 & 0.27870 \\
$\mathrm{O}$ & 0.39262 & 0.29641 & -1.14693 \\
$\mathrm{C}$ & -1.17807 & 1.90662 & -0.31228 \\
$\mathrm{H}$ & -1.91470 & 1.62451 & -1.06352 \\
$\mathrm{H}$ & -1.71275 & 2.25325 & 0.57542 \\
$\mathrm{H}$ & -0.55171 & 2.71499 & -0.69413 \\
$\mathrm{O}$ & -2.39111 & -0.48859 & -0.00470 \\
$\mathrm{H}$ & -2.85427 & -1.28041 & 0.27983 \\
$\mathrm{H}$ & -1.12878 & -0.49218 & 1.63451 \\
\hline
\end{tabular}

ION-8

\begin{tabular}{cccc}
\hline C & 0.49343 & -0.65892 & -0.18118 \\
C & -0.21501 & -0.90739 & 1.16826 \\
H & 0.07728 & -0.17771 & 1.92216 \\
H & -0.05595 & -1.92294 & 1.53363 \\
C & 1.09854 & 0.75212 & -0.26713 \\
C & -0.07124 & 1.69055 & -0.58168 \\
H & 0.10429 & 2.68588 & -0.16424 \\
H & -0.19806 & 1.77896 & -1.66605 \\
O & -1.26934 & 1.25730 & 0.02898 \\
O & 1.75413 & 1.01977 & 0.94964 \\
N & -1.66224 & -0.08596 & -0.34739 \\
O & -1.60231 & -0.78339 & 0.84179 \\
O & -0.62575 & -0.63492 & -1.08625 \\
H & 1.81116 & 0.78075 & -1.10499 \\
H & 2.20284 & 1.86542 & 0.87956 \\
C & 1.45290 & -1.74877 & -0.59658 \\
H & 1.78885 & -1.58810 & -1.62354 \\
H & 2.32509 & -1.72838 & 0.06201 \\
H & 0.97466 & -2.72783 & -0.53030 \\
\hline
\end{tabular}


TS1

\begin{tabular}{llll}
$\mathrm{C}$ & 1.75128 & -0.27552 & 0.77560 \\
$\mathrm{C}$ & 0.57253 & 0.44897 & 0.12600 \\
$\mathrm{O}$ & 0.06100 & -0.47937 & -0.97221 \\
$\mathrm{~N}$ & -1.12060 & -0.99345 & -0.50174 \\
$\mathrm{O}$ & -2.10271 & -0.26486 & -0.77666 \\
$\mathrm{O}$ & -1.00761 & -1.36555 & 0.67630 \\
$\mathrm{H}$ & 2.25073 & 0.41242 & 1.46627 \\
$\mathrm{C}$ & -0.58009 & 0.62043 & 1.05838 \\
$\mathrm{H}$ & -0.46761 & 0.39280 & 2.11048 \\
$\mathrm{C}$ & -1.75068 & 1.14789 & 0.52168 \\
$\mathrm{H}$ & -2.64246 & 1.20752 & 1.13386 \\
$\mathrm{H}$ & -1.70750 & 1.83008 & -0.31662 \\
$\mathrm{O}$ & 2.70040 & -0.66529 & -0.17976 \\
$\mathrm{H}$ & 2.24160 & -1.24630 & -0.79552 \\
$\mathrm{H}$ & 1.36904 & -1.12955 & 1.34687 \\
$\mathrm{C}$ & 1.02841 & 1.68268 & -0.63814 \\
$\mathrm{H}$ & 1.42208 & 2.42522 & 0.05930 \\
$\mathrm{H}$ & 1.82741 & 1.39357 & -1.32224 \\
$\mathrm{H}$ & 0.21352 & 2.12228 & -1.21273 \\
\hline
\end{tabular}

TS2

\begin{tabular}{llll}
\hline C & -1.26008 & 1.67591 & 0.32602 \\
C & -0.61147 & 0.30587 & 0.33025 \\
O & -0.05709 & 0.04994 & -1.07149 \\
N & 1.30275 & 0.15241 & -0.95910 \\
O & 1.84409 & -0.93803 & -0.65110 \\
O & 1.62243 & 1.14621 & -0.29110 \\
H & -1.67637 & 1.88771 & 1.31522 \\
C & 0.57150 & 0.20340 & 1.23179 \\
H & 0.80408 & 1.01623 & 1.90631 \\
C & 1.30440 & -0.98248 & 1.20711 \\
H & 2.22220 & -1.04840 & 1.77937 \\
H & 0.82592 & -1.92609 & 0.98444 \\
H & -0.52142 & 2.43677 & 0.07495 \\
C & -1.65349 & -0.81085 & 0.46450 \\
H & -2.21662 & -0.65476 & 1.38904 \\
H & -1.15544 & -1.78523 & 0.52581 \\
O & -2.57882 & -0.77510 & -0.58820 \\
H & -2.08022 & -0.90132 & -1.40196 \\
H & -2.07135 & 1.69295 & -0.40235 \\
\hline
\end{tabular}

TS3

\begin{tabular}{llll}
\hline C & 1.92715 & 0.47690 & 0.11153 \\
C & 0.64935 & 0.09808 & -0.61059 \\
O & 0.31611 & -1.31225 & -0.19505 \\
N & -0.83566 & -1.20398 & 0.55615 \\
O & -1.86489 & -1.29485 & -0.14132 \\
O & -0.76206 & -0.25894 & 1.35271 \\
H & 2.26520 & 1.46036 & -0.23093 \\
C & -0.56164 & 0.93366 & -0.33857 \\
C & -1.70020 & 0.48883 & -1.00888 \\
H & -2.65121 & 0.98237 & -0.84196 \\
H & -1.60105 & -0.06604 & -1.93339 \\
O & 2.94791 & -0.44001 & -0.18045 \\
H & 2.62630 & -1.30484 & 0.09356 \\
H & 0.83525 & -0.02338 & -1.68117 \\
H & 1.72137 & 0.53497 & 1.18821 \\
C & -0.48535 & 2.25266 & 0.37497 \\
H & -0.08103 & 3.02380 & -0.28886 \\
H & -1.48494 & 2.56635 & 0.68139 \\
H & 0.14734 & 2.20191 & 1.26216 \\
\hline
\end{tabular}

TS4

\begin{tabular}{cccc}
\hline C & -0.46778 & 0.54757 & -0.76470 \\
O & -0.45405 & -0.92457 & -1.01185 \\
N & 0.69043 & -1.39201 & -0.38900 \\
O & 0.49770 & -1.66602 & 0.81368 \\
O & 1.66202 & -0.68346 & -0.67500 \\
C & 0.59169 & 0.84964 & 0.25538 \\
C & 0.45180 & 0.22073 & 1.49019 \\
H & 1.24865 & 0.32445 & 2.21984 \\
H & -0.52884 & -0.03673 & 1.86286 \\
C & -1.93321 & 0.81533 & -0.40456 \\
H & -2.52899 & 0.66338 & -1.31571 \\
H & -2.04869 & 1.85905 & -0.10009 \\
O & -2.39492 & 0.01005 & 0.64411 \\
H & -2.15625 & -0.89621 & 0.41450 \\
C & 1.58948 & 1.93888 & -0.00987 \\
H & 1.95239 & 1.90169 & -1.03866 \\
H & 1.13503 & 2.92114 & 0.15775 \\
H & 2.44089 & 1.84603 & 0.66703 \\
H & -0.22494 & 1.04033 & -1.71080 \\
\hline
\end{tabular}


TS5

\begin{tabular}{lccc}
$\mathrm{C}$ & -0.09344 & 0.93448 & -0.33785 \\
$\mathrm{C}$ & -1.55640 & 0.92991 & -0.62925 \\
$\mathrm{H}$ & -1.78217 & 0.95542 & -1.69628 \\
$\mathrm{H}$ & -2.09193 & 1.71610 & -0.09605 \\
$\mathrm{C}$ & 0.61154 & -0.07187 & -1.00575 \\
$\mathrm{C}$ & 2.04834 & -0.40606 & -0.70728 \\
$\mathrm{H}$ & 2.27969 & -1.37386 & -1.17226 \\
$\mathrm{O}$ & -0.35168 & -1.64761 & -0.19102 \\
$\mathrm{~N}$ & -1.13339 & -0.98698 & 0.52581 \\
$\mathrm{O}$ & -2.12948 & -0.38486 & -0.19516 \\
$\mathrm{O}$ & -0.62934 & -0.20755 & 1.34802 \\
$\mathrm{H}$ & 2.71203 & 0.33970 & -1.16304 \\
$\mathrm{O}$ & 2.32053 & -0.41811 & 0.66950 \\
$\mathrm{H}$ & 1.56506 & -0.83825 & 1.09930 \\
$\mathrm{C}$ & 0.53635 & 2.06895 & 0.41882 \\
$\mathrm{H}$ & 0.71899 & 2.91151 & -0.25671 \\
$\mathrm{H}$ & -0.12362 & 2.41151 & 1.21788 \\
$\mathrm{H}$ & 1.48656 & 1.75606 & 0.85013 \\
$\mathrm{H}$ & 0.21044 & -0.43672 & -1.94653 \\
\hline
\end{tabular}

TS6

\begin{tabular}{llll}
\hline $\mathrm{C}$ & 0.75845 & 0.85270 & 0.10835 \\
$\mathrm{C}$ & 1.02557 & 0.00482 & 1.31049 \\
$\mathrm{H}$ & 0.43250 & 0.26488 & 2.18822 \\
$\mathrm{H}$ & 2.08732 & -0.02132 & 1.56057 \\
$\mathrm{C}$ & -0.56416 & 0.84675 & -0.35013 \\
$\mathrm{O}$ & -0.65654 & -1.11765 & -0.79875 \\
$\mathrm{~N}$ & 0.48394 & -1.41517 & -0.38271 \\
$\mathrm{O}$ & 0.56940 & -1.37219 & 0.99848 \\
$\mathrm{O}$ & 1.44297 & -0.83859 & -0.90567 \\
$\mathrm{C}$ & -1.78560 & 0.71959 & 0.53557 \\
$\mathrm{H}$ & -1.57367 & 0.06559 & 1.38920 \\
$\mathrm{H}$ & -2.02967 & 1.71569 & 0.92396 \\
$\mathrm{O}$ & -2.91447 & 0.29512 & -0.17649 \\
$\mathrm{H}$ & -2.71873 & -0.59316 & -0.49017 \\
$\mathrm{H}$ & -0.76552 & 1.35479 & -1.29183 \\
$\mathrm{C}$ & 1.80560 & 1.78948 & -0.41793 \\
$\mathrm{H}$ & 1.58705 & 2.05785 & -1.45350 \\
$\mathrm{H}$ & 1.82613 & 2.71342 & 0.16910 \\
$\mathrm{H}$ & 2.79706 & 1.33488 & -0.37527 \\
\hline
\end{tabular}

TS7

\begin{tabular}{llll}
\hline $\mathrm{C}$ & -0.09667 & 0.05121 & 1.13424 \\
$\mathrm{H}$ & 0.31064 & -0.66782 & 1.83055 \\
$\mathrm{C}$ & -1.52896 & 0.41264 & 1.15042 \\
$\mathrm{H}$ & -1.72740 & 1.48061 & 1.23759 \\
$\mathrm{H}$ & -2.10012 & -0.15161 & 1.88589 \\
$\mathrm{C}$ & 0.71753 & 0.66282 & 0.16894 \\
$\mathrm{C}$ & 2.10403 & 0.09555 & -0.03232 \\
$\mathrm{H}$ & 2.38555 & 0.26677 & -1.08176 \\
$\mathrm{O}$ & -0.25665 & -0.03705 & -1.39718 \\
$\mathrm{~N}$ & -1.14201 & -0.70135 & -0.80718 \\
$\mathrm{O}$ & -2.08605 & 0.09375 & -0.21484 \\
$\mathrm{O}$ & -0.74857 & -1.58866 & -0.03215 \\
$\mathrm{C}$ & 0.53913 & 2.09667 & -0.26657 \\
$\mathrm{H}$ & -0.51142 & 2.37474 & -0.34089 \\
$\mathrm{H}$ & 1.03847 & 2.76095 & 0.44594 \\
$\mathrm{H}$ & 2.81586 & 0.65515 & 0.58763 \\
$\mathrm{O}$ & 2.20482 & -1.25052 & 0.33183 \\
$\mathrm{H}$ & 1.47181 & -1.71149 & -0.09574 \\
$\mathrm{H}$ & 0.99193 & 2.24856 & -1.24849 \\
\hline
\end{tabular}

TS8

\begin{tabular}{llll}
\hline $\mathrm{C}$ & 0.53669 & 0.70083 & 1.04439 \\
$\mathrm{H}$ & 0.84284 & 1.68030 & 1.38624 \\
$\mathrm{C}$ & 1.41755 & -0.47340 & 1.26023 \\
$\mathrm{H}$ & 0.97515 & -1.28322 & 1.83957 \\
$\mathrm{H}$ & 2.38647 & -0.19267 & 1.67148 \\
$\mathrm{C}$ & -0.70699 & 0.49768 & 0.43003 \\
$\mathrm{C}$ & -1.52182 & 1.68768 & 0.01435 \\
$\mathrm{H}$ & -0.87865 & 2.52317 & -0.26292 \\
$\mathrm{H}$ & -2.15525 & 1.41886 & -0.83139 \\
$\mathrm{O}$ & 0.03713 & -0.22781 & -1.27901 \\
$\mathrm{~N}$ & 1.25697 & -0.15178 & -0.98877 \\
$\mathrm{O}$ & 1.63658 & -1.11018 & -0.07692 \\
$\mathrm{O}$ & 1.68372 & 0.96465 & -0.66840 \\
$\mathrm{C}$ & -1.50772 & -0.77716 & 0.65442 \\
$\mathrm{H}$ & -0.83779 & -1.62165 & 0.84670 \\
$\mathrm{H}$ & -2.13034 & -0.62525 & 1.54471 \\
$\mathrm{O}$ & -2.39262 & -1.05304 & -0.39579 \\
$\mathrm{H}$ & -1.84529 & -1.23449 & -1.16684 \\
$\mathrm{H}$ & -2.18063 & 1.99469 & 0.83426 \\
\hline
\end{tabular}




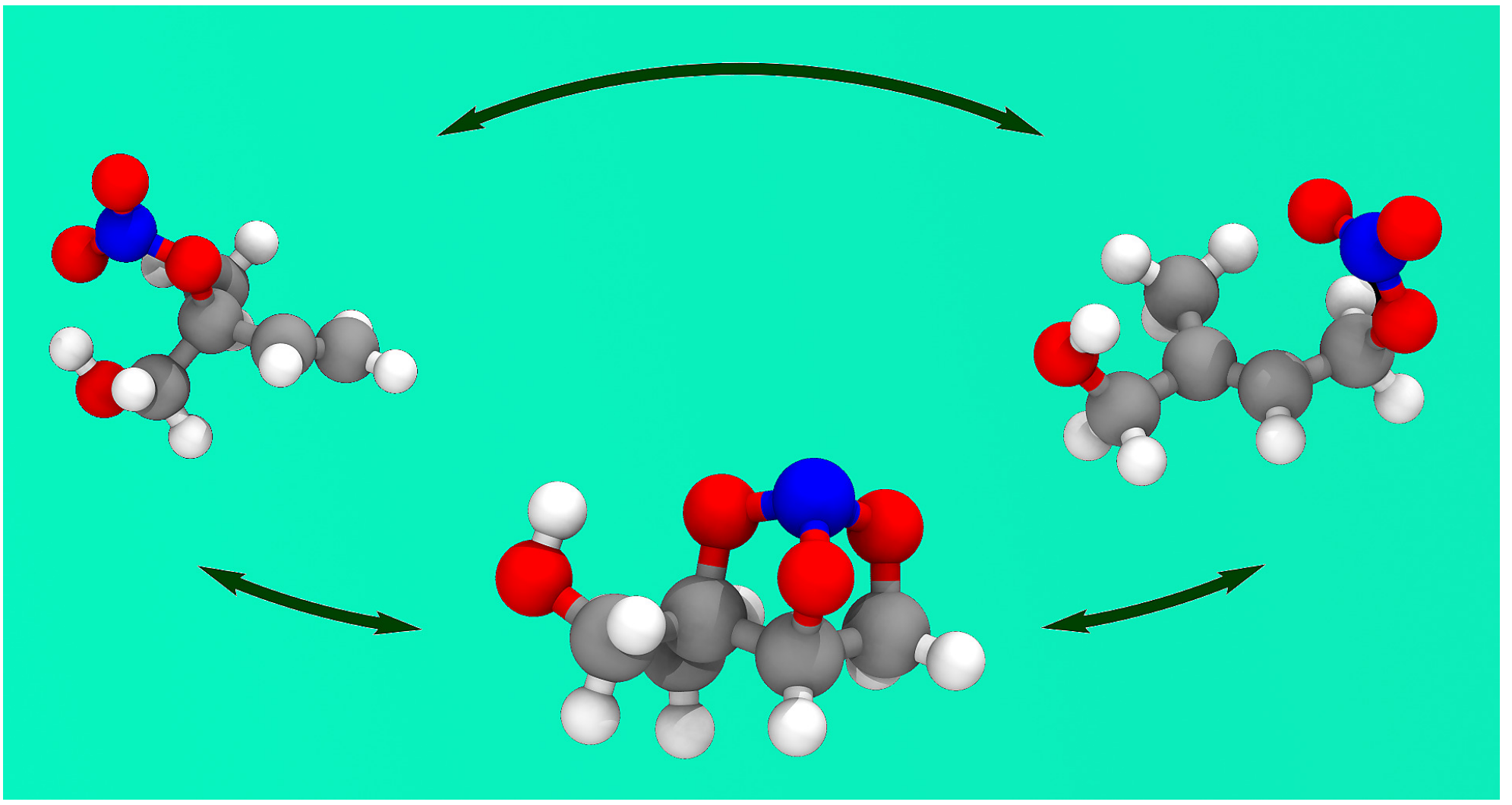

